\title{
A Comparative Study of Estimation by Analogy using Data Mining Techniques
}

\author{
Geeta Nagpal ${ }^{\star}$, Moin Uddin ${ }^{* \star}$ and Arvinder Kaur ${ }^{\star \star *}$
}

\begin{abstract}
Software Estimations provide an inclusive set of directives for software project developers, project managers, and the management in order to produce more realistic estimates based on deficient, uncertain, and noisy data. A range of estimation models are being explored in the industry, as well as in academia, for research purposes but choosing the best model is quite intricate. Estimation by Analogy (EbA) is a form of case based reasoning, which uses fuzzy logic, grey system theory or machine-learning techniques, etc. for optimization. This research compares the estimation accuracy of some conventional data mining models with a hybrid model. Different data mining models are under consideration, including linear regression models like the ordinary least square and ridge regression, and nonlinear models like neural networks, support vector machines, and multivariate adaptive regression splines, etc. A precise and comprehensible predictive model based on the integration of GRA and regression has been introduced and compared. Empirical results have shown that regression when used with GRA gives outstanding results; indicating that the methodology has great potential and can be used as a candidate approach for software effort estimation.
\end{abstract}

Keywords-Software Estimations, Estimation by Analogy, Grey Relational Analysis, Robust Regression, Data Mining Techniques

\section{INTRODUCTION}

Software development is a creative process where each person's efficiency is different. It is difficult to plan and estimate at the beginning as most software projects have deficient information and vague associations amongst effort drivers and the required effort. Software developers and researchers are using different methods and are more concerned about accurately predicting the effort of the software product being developed. Even a small enhancement in the prediction accuracy and validity are highly valued by researchers and software developers. During the last couple of years, research on software effort estimation has drifted from formal methods like Cocomo, Cocomo II, Function point and SLIM to Estimation by Analogy (EbA). In $\mathrm{E} b \mathrm{~A}$, the effort required to develop a new software project requires the gathering of the particulars of the desired project. The particulars are then compared to a past project from the dataset having approximately the same specifications, but the challenge is the inconsistency in the struc-

\footnotetext{
※ The authors would like to thank the Promise Repository for providing such valuable datasets for our being able to carry out our research work

Manuscript received April 20, 2012; first revision July 4, 2012; accepted October 8, 2012.

Corresponding Author: Geeta Nagpal

* Dept. of Computer Science and Engineering, National Institute of Technology, Jalandhar (sikkag@gmail.com)

**Delhi Technological University, Delhi, India (prof_moin@yahoo.com)

*** University School of IT, Gurugobind Singh Indraprastha University, Delhi, India (arvinderkaurtakkar@yahoo.com)
} 
ture of the datasets used and in the feature set classification. The motivation behind EbA is that comparable software projects have similar costs.

$\mathrm{E} b \mathrm{~A}$ methods range from machine learning methods, regression techniques, the Grey System Theory (GST), and soft computing methods to a combination of these. GST is a recently developed system engineering theory that was first established by Deng in 1982 [1-3]. It draws out valuable information by generating and developing the partially known information. It has been applied in different areas of image processing [4], mobile communication [5], machine vision inspection [6], decision making [7], stock price prediction [8], and system control [9]. Some of the research carried out using EbA has been discussed. Mukhopadhyay et al. [10] developed ESTOR, which is a CBR tool to estimate project effort. The metrics used by ESTOR are the function point components and inputs to the intermediate COCOMO model. Shepperd et al. [11], developed ANGEL, which is a tool that supports the collection, storage, and identification of the most analogous projects, in order to estimate the effort for a new project. ANGEL uses Euclidean distance as the similarity metric in $\mathrm{n}$ dimensional space. Angelis et al. [12] uses a statistical simulation modus operandi to improve estimation by analogy. They investigated the problem of determining the most favourable method parameter configuration before application. The ANALOGY-X [13] tool provides a sound statistical basis for analogy based estimation using the Mantel's correlation randomization test. It removes the need for heuristic search, and greatly improves the algorithmic performance of the model. Baskeles et al., in [14] propose a machinelearning based model for software effort estimation and tested it on three different data sets, namely, NASA, USC, and SoftLab Data Repository (SDR). Idri et al. [15] suggested an approach based on reasoning by analogy, fuzzy sets, and linguistic quantifiers for software effort estimation when the project is described by either categorical or numerical data. Azzeh et al. in [16] integrated an analogy-based estimation with fuzzy numbers to improve the performance of software project effort estimation during its early development stages, using all of the available early data. They proposed a new similarity measure technique based on fuzzy numbers. Shepperd et al. [17] proposed a Grey Relational Analysis based software project effort (GRACE) prediction method, including a feature subset selection. Hsu and Huang [18] integrated six different weighted measures with the GRA method, namely, non-weight, distance-based weight, correlative weight, linear weight, nonlinear weight, and maximal weight, were applied to 127 projects from the ISBSG data set. GRACE ${ }^{+}[19]$ addresses some of the theoretical challenges in applying GRA to outlier detection, feature subset selection, and effort prediction. In [20], Chiu et al. used genetic algorithms to optimize the analogy weights for software effort estimation. In [20], they integrated GA with GRA. Kosti et al.[21] suggested a new algorithm that initiates the notion of distance. It uses the similarity between distributions of distances instead of leaving one out cross validation to find the number of appropriate neighbours to be used for estimating the effort for new projects. AQUA [22] combines ideas from two known analogy-based estimation techniques: case-based reasoning and collaborative filtering. The method is applicable to predict efforts related to any object in the requirements, features, or project levels. In this research study, GRA, which is a technique of GST, utilizes the concept of absolute point-to-point distance between cases [17]. GRA is used to find the number of comparative projects $(k)$ that are closest to the reference project from the total of $n$ projects. The projects are ranked based on their Grey Relational Grade's (GRG). Regression techniques namely, the Ordinary Least Square (OLS), Robust Regression (RR) techniques and Stepwise Regression (SWR) are applied to the $k$ most influential projects in order to estimate the effort of the reference project. The value of $k$ varies 
with each reference project. The results obtained have shown an improvement over the conventional data mining techniques and also a significant improvement over GRACE [17], GRACE ${ }^{+}$ [19], and FGRA [23]. A brief literature overview of the various analogy based approaches for software effort estimation is provided in Table 1 . The remainder of the paper is organized as follows: Section II is a brief review of GRA and various regression techniques. Section III describes the proposed software effort prediction mechanisms using GREAT_RM, the validation and evaluation criteria, and the datasets used in the methodology. Section IV provides the experimental results of GREAT_RM and its comparison with some of the conventional data mining methods for software cost estimation along with their statistical significance. Section $\mathrm{V}$ provides, comparison of the results with some previously published results. Section VI presents threats to validity. The conclusion and directions for future work are presented in Section VII.

Table 1. Literature Overview of the Application of Analogy Based Approaches for Software Effort Estimation

\begin{tabular}{|c|c|c|c|c|c|c|c|c|c|c|c|c|c|}
\hline $\begin{array}{l}\text { Sr } \\
\text { No. }\end{array}$ & Author/Year & Title & $\begin{array}{c}\text { Journal/ } \\
\text { Conference }\end{array}$ & $\begin{array}{l}\text { Approach/ } \\
\text { Technique }\end{array}$ & Datasets & \multicolumn{7}{|c|}{ Performance } & $\begin{array}{l}\text { Testing } \\
\text { Mode }\end{array}$ \\
\hline \multirow{3}{*}{1.} & \multirow{3}{*}{$\begin{array}{c}\text { Srinivasan K, } \\
\text { Fisher D, } \\
(1995)[24]\end{array}$} & \multirow{3}{*}{$\begin{array}{c}\text { Machine Learning } \\
\text { Approaches to } \\
\text { Estimating Soft- } \\
\text { ware Develop- } \\
\text { ment Efforts }\end{array}$} & \multirow{3}{*}{$\begin{array}{c}\text { IEEE Transac- } \\
\text { tions on Soft- } \\
\text { ware } \\
\text { Engineering }\end{array}$} & \multirow{3}{*}{$\begin{array}{l}\text { ANN, } \\
\text { CART }\end{array}$} & \multirow{3}{*}{$\begin{array}{c}\text { Kemerer, } \\
\text { COCOMO-81 }\end{array}$} & & & \multirow{2}{*}{\multicolumn{2}{|c|}{$\begin{array}{c}\text { MRE } \\
364 \\
70 \\
\end{array}$}} & \multirow{2}{*}{$\begin{array}{c}\mathbf{R}^{\mathbf{2}} \\
0.83 \\
0.80\end{array}$} & \multicolumn{2}{|c|}{ Eqn } & \multirow{3}{*}{ Holdout } \\
\hline & & & & & & \multirow{2}{*}{\multicolumn{2}{|c|}{$\begin{array}{l}\text { CartX } \\
\text { B.Prpgt } \\
\text { Func pt } \\
\text { Cocomo } \\
\text { Slim }\end{array}$}} & & & & \multicolumn{2}{|c|}{$\begin{array}{c}102.5+0.075 x \\
78.13+0.88 x\end{array}$} & \\
\hline & & & & & & & & \multicolumn{2}{|c|}{$\begin{array}{l}10.3 \\
610 \\
772\end{array}$} & $\begin{array}{l}0.58 \\
0.70 \\
0.89\end{array}$ & \multicolumn{2}{|c|}{$\begin{array}{c}-37+0.96 x \\
27.7+0.156 x \\
49.9+0.082 x\end{array}$} & \\
\hline \multirow{6}{*}{2.} & \multirow{6}{*}{$\begin{array}{l}\text { Shepperd N. } \\
\text { Schofield C, } \\
(1997)[11]\end{array}$} & \multirow{6}{*}{$\begin{array}{l}\text { Estimating Soft- } \\
\text { ware Project } \\
\text { Efforts Using } \\
\text { Analogies }\end{array}$} & \multirow{6}{*}{$\begin{array}{c}\text { IEEE Transac- } \\
\text { tions on Soft- } \\
\text { ware } \\
\text { Engineering }\end{array}$} & \multirow{6}{*}{$\begin{array}{c}\text { OLS, Case } \\
\text { based } \\
\text { reasoning }\end{array}$} & \multirow{6}{*}{$\begin{array}{l}\text { Desharnais } \\
\text { Finnish } \\
\text { Kemerer } \\
\text { Mermaid } \\
\text { Telecom }\end{array}$} & Dataset & $\begin{array}{c}\text { MMRE } \\
(\%) \\
\end{array}$ & Reg1 & Reg2 & \begin{tabular}{|c|c|}
$\begin{array}{c}\text { Pred } \\
(25 \%)\end{array}$ \\
\end{tabular} & Reg1 & Reg2 & \multirow{6}{*}{$\begin{array}{c}\text { Cross } \\
\text { Validation }\end{array}$} \\
\hline & & & & & & \begin{tabular}{|c|} 
Desharnais \\
1
\end{tabular} & 37 & 41 & 41 & 47 & 45 & 45 & \\
\hline & & & & & & \begin{tabular}{|c|} 
Desharnais \\
2
\end{tabular} & 29 & 29 & 29 & 47 & 48 & 48 & \\
\hline & & & & & & \begin{tabular}{|c|} 
Desharnais \\
3 \\
\end{tabular} & 26 & 36 & 49 & 70 & 30 & 50 & \\
\hline & & & & & & Mermaid E & 53 & 62 & 62 & 39 & 27 & 27 & \\
\hline & & & & & & Mermaid N & 60 & -- & -- & 25 & -- & -- & \\
\hline \multirow{5}{*}{3.} & \multirow{5}{*}{$\begin{array}{l}\text { Witting G, } \\
\text { Finnie G., } \\
(1997)[25]\end{array}$} & \multirow{5}{*}{$\begin{array}{l}\text { Estimating Soft- } \\
\text { ware Develop- } \\
\text { ment Efforts with } \\
\text { Connectionist } \\
\text { Models }\end{array}$} & \multirow{5}{*}{$\begin{array}{l}\text { Information } \\
\text { and Software } \\
\text { Technology }\end{array}$} & & & ARE & & $\%$ & & & Cum \% & & \\
\hline & & & & & & $0-10 \%$ & & 40.0 & & & 40.0 & & \\
\hline & & & & ANN & Simulated data & $11-25 \%$ & & 36.7 & & & 76.7 & & Holdout \\
\hline & & & & & & $26-50 \%$ & & 20.0 & & & 96.7 & & \\
\hline & & & & & & $>50 \%$ & & 3.3 & & & 100 & & \\
\hline & & & & & & Corr & relation & & & & .752 & & \\
\hline & & $\begin{array}{l}\text { Can Genetic } \\
\text { Programming }\end{array}$ & & & & & MSE & & & & 1.13 & & \\
\hline 4 & Burgess C.J., & Improve Software & Information & Genetic & Desharnais & & $\operatorname{ed}(25)$ & & & & 4.2 & & Random \\
\hline 4 & (2001)[26] & Effort Estimation? & $\begin{array}{l}\text { Technology } \\
\text { Telo }\end{array}$ & Algorithm & Desmamais & Pred & $\mathrm{d}(25) \%$ & & & & 23.3 & & \\
\hline & & $\begin{array}{l}\text { A Comparative } \\
\text { Evaluation }\end{array}$ & & & & & IMRE & & & & 4.55 & & \\
\hline & & & & & & & MMRE & & & & 75 & & \\
\hline & & & & & & & MSF & & & & $=2.90$ & & \\
\hline & & & & & & & NSSE & & & & $=5.4$ & & \\
\hline & & & & & & & $\mathbf{P}^{2}$ & & & $\operatorname{Tr}=$ & $=0.44$ & & \\
\hline & & Software Project & & & & & $\mathbf{R}^{-}$ & & & $\mathrm{Ts}=$ & $=0.40$ & & \\
\hline 5 & Essam et.al., & Effort Estimation & IFEF & Genetic & ISBSG & & IMRF & & & $\operatorname{Tr}=$ & $=2.67$ & & Random \\
\hline & $(2002)[27]$ & Using Genetic & TEEE & Algorithm & ISBSE & & IVIRE & & & & $=1.91$ & & \\
\hline & & Programming & & & & Pred & 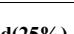 & & & $\operatorname{Tr}=$ & $=0.19$ & & \\
\hline & & & & & & Prea & $a(25 \%)$ & & & $\mathrm{Ts}=$ & $=0.21$ & & \\
\hline & & & & & & Pred & $d(50 \%)$ & & & & $=0.39$ & & \\
\hline & & & & & & Pred & $a(50 \%)$ & & & & $=0.40$ & & \\
\hline & & Estimating Soft- & Eighth IEEE & & & & IMRE & & & & 22.5 & & \\
\hline 6 & $\begin{array}{l}\text { Idri et al., } \\
(2002)[28]\end{array}$ & $\begin{array}{c}\text { ware Project } \\
\text { Efforts by Analo- } \\
\text { gy Based on } \\
\text { Linguistic Values }\end{array}$ & $\begin{array}{l}\text { International } \\
\text { Symposium on } \\
\text { Software } \\
\text { Metrics }\end{array}$ & $\begin{array}{c}\text { Fuzzy } \\
\text { Analogy }\end{array}$ & & & $\operatorname{Pred}\left(25^{\circ}\right.$ & & & & 52.14 & & - \\
\hline
\end{tabular}


Table 1. <Continue>

\begin{tabular}{|c|c|c|c|c|c|c|c|c|c|c|c|c|c|c|c|}
\hline $\begin{array}{l}\text { Sr } \\
\text { No. }\end{array}$ & Author/Year & Title & $\begin{array}{c}\text { Journal/ } \\
\text { Conference }\end{array}$ & $\begin{array}{l}\text { Approach/ } \\
\text { Technique }\end{array}$ & Datasets & \multicolumn{9}{|c|}{ Performance } & Testing \\
\hline \multirow[b]{2}{*}{7} & \multirow[b]{2}{*}{$\begin{array}{l}\text { Huang X, } \\
\text { Caretz L.F., } \\
\text { and Ren J., } \\
(2003)[29]\end{array}$} & \multirow[b]{2}{*}{$\begin{array}{l}\text { A Neuro-Fuzzy } \\
\text { Model for } \\
\text { Software Cost } \\
\text { Estimation }\end{array}$} & \multirow{2}{*}{\begin{tabular}{|} 
Third Interna- \\
tional Confer- \\
ence on \\
Quality \\
Software, \\
(QSIC'03)
\end{tabular}} & \multirow{2}{*}{$\begin{array}{l}\text { Neuro-Fuzzy, } \\
\text { COCOMO II }\end{array}$} & \multirow[b]{2}{*}{$\begin{array}{c}\text { COCOMO'81+ } \\
6 \text { industry } \\
\text { projects. }\end{array}$} & \multicolumn{5}{|c|}{ Pred $(20 \%)$} & \multicolumn{4}{|c|}{86} & \\
\hline & & & & & & \multicolumn{5}{|c|}{ Pred(30\%) } & \multicolumn{4}{|c|}{92} & All \\
\hline \multirow{6}{*}{8} & \multirow{6}{*}{$\begin{array}{c}\text { Song Q., } \\
\text { Shepperd } \\
\text { M., and } \\
\text { Carolyn M, } \\
(2005)[17]\end{array}$} & \multirow{6}{*}{$\begin{array}{l}\text { Using Grey } \\
\text { Relational } \\
\text { Analysis to } \\
\text { Predict Soft- } \\
\text { ware Efforts } \\
\text { with Small } \\
\text { Data Sets }\end{array}$} & \multirow{6}{*}{$\begin{array}{c}\text { IEEE Interna- } \\
\text { tional Soft- } \\
\text { ware Metrics } \\
\text { Symposium }\end{array}$} & \multirow{6}{*}{$\begin{array}{c}\text { Analogy, } \\
\text { Grey Rela- } \\
\text { tional Analy- } \\
\text { sis }\end{array}$} & & \multicolumn{2}{|c|}{ MMRE } & \multicolumn{3}{|c|}{ MdMRE } & Pred & $(25)^{\circ}$ & & Bias & \\
\hline & & & & & Albrecht & 60.25 & & & 1.35 & & & 2.63 & & -12.13 & \\
\hline & & & & & NASA & 32.88 & & & 8.38 & & & 6.67 & & 17.34 & Jack \\
\hline & & & & & COCOMO81 & 76.09 & & & 0.52 & & & 0.63 & & -18.89 & Knifing \\
\hline & & & & & Desharnais & 49.83 & & & 3.93 & & & 0.00 & & -16.52 & \\
\hline & & & & & Kemerer & 58.83 & & & 6.94 & & & 6.67 & & -7.07 & \\
\hline & & & & & & Mean & (Pre & d(30) & & & Med & $\operatorname{dian}(\mathrm{F}$ & Pred( & (30)) & \\
\hline & & $\begin{array}{l}\text { Feature Subset } \\
\text { Selection Can }\end{array}$ & & Feature & COCOCMO'81 & & 51.3 & & & & & 7.6 & 66 & & \\
\hline 0 & Bohem et. al., & Improve & & Subset & NASA60 & & 81.3 & & & & & 7.3 & 32 & & \\
\hline , & (2005)[30] & Software Cost & PROMISE'05 & (WRAPPER) & Project04 & & 66.7 & & & & & 6.9 & 92 & & Kandom \\
\hline & & Estimation & & COCOMO & Project03 & & 55.8 & & & & & 15. & .65 & & \\
\hline & & & & & Project02 & & 97.1 & & & & & 15. & .16 & & \\
\hline & & & & & & & & & MRE & & PREI & D 20 & PR & ED 25 & \\
\hline & & $\begin{array}{l}\text { Software } \\
\text { Produvity }\end{array}$ & & & & $\begin{array}{l}\text { Fitting acc } \\
\text { for all } 52 \mathrm{pr}\end{array}$ & $\begin{array}{l}\text { uracy } \\
\text { ojects }\end{array}$ & & $.28 \%$ & & 44.2 & $2 \%$ & & $3.8 \%$ & \\
\hline 10 & $\begin{array}{l}\text { Angelis L, } \\
\text { Stamelos I, } \\
(2005)[31]\end{array}$ & $\begin{array}{c}\text { and Effort } \\
\text { Prediction with } \\
\text { Ordinal Re- }\end{array}$ & $\begin{array}{c}\text { Information } \\
\text { and Software } \\
\text { Technology }\end{array}$ & $\begin{array}{l}\text { sion, Ordinal } \\
\text { regression }\end{array}$ & $\begin{array}{c}\text { COCOMO-81, } \\
\text { Maxwell, } \\
\text { ISBSG R7 }\end{array}$ & $\begin{array}{r}\text { Fitting acc } \\
\text { for learn } \\
\text { datase }\end{array}$ & iracy & & $1.38 \%$ & & 40.5 & $5 \%$ & & $0.0 \%$ & Holdout \\
\hline & & gression & & & & $\begin{array}{r}\text { Predicti } \\
\text { accuracy fo } \\
\text { test data }\end{array}$ & $\begin{array}{l}\text { ve } \\
\text { or the } \\
\text { set }\end{array}$ & & $5.06 \%$ & & 30.0 & $0 \%$ & & $0.0 \%$ & \\
\hline 11 & $\begin{array}{c}\text { Sheta A F, } \\
\text { A.(2006)[32] }\end{array}$ & \begin{tabular}{|c|} 
Estimation of \\
the COCOMO \\
Model Parame- \\
ters Using \\
Genetic Algo- \\
rithms for \\
NASA Soft- \\
ware Projects \\
\end{tabular} & $\begin{array}{c}\text { Journal of } \\
\text { Computer } \\
\text { Science }\end{array}$ & $\begin{array}{c}\text { Genetic } \\
\text { Algorithm, } \\
\text { COCOMO }\end{array}$ & NASA & & VAF & & & & & 96. & 31 & & Random \\
\hline & & & & & & Dataset & MI & MRE & Pr & red 25 & & $\mathbf{V A R}_{\mathrm{r}}$ & & MFWV & \\
\hline & & & & & & Albrecht & & 15 & & 20 & & 21 & & 34 & \\
\hline & Auer M, & Optimal Project & & & & Desharnais & & 12 & & 11 & & 20 & & 43 & \\
\hline & Trendowicz & Weights in & IEEE Trans- & & ESA, & Desharnais & & 13 & & 19 & & 23 & & 65 & \\
\hline 12 & $\begin{array}{l}\text { A, } \\
\text { Biffl S }\end{array}$ & Analogy-Based & actions on & Case base & Desharnais, & Desharnais & & 21 & & 20 & & 30 & & 18 & Cross \\
\hline & Haunschmid & ost Estima- & Software & reasoning & Kemerer, & ESA 29 & & 8 & & 7 & & 1 & & 58 & Validation \\
\hline & E, Graser B & $\begin{array}{l}\text { tion: } \\
\text { Imnroyement }\end{array}$ & Engineering & & Albrecht & ESA 13 & & 3 & & 4 & & 9 & & 29 & \\
\hline & (2006)[33] & and Limitations & & & & Kemerer 1 & & 2 & & 16 & & 3 & & 34 & \\
\hline & & & & & & Laturi 12 & & 6 & & 14 & & 3 & & 8 & \\
\hline & & & & & & Laturi 11 & & 16 & & 25 & & 20 & & 27 & \\
\hline & & & $22^{\text {nd }}$ Interna- & & & & IMRE & & & & & Pred & (30) & & \\
\hline & Baskeles B & Estimation & tional Sympo- & MLP, & & & 22.11 & & & & & 73.2 & & & \\
\hline 13 & Burnan B & Using Machine & $\begin{array}{c}\text { sium on } \\
\text { Computer and }\end{array}$ & SVM, & & & 10.94 & & & & & 33 & & & - \\
\hline & $(2007)[14]$ & Learning & Information & Decision Tree & & & 25.72 & & & & & 75 & & & \\
\hline & & & Science & & & & 12.85 & & & & & 83. & & & \\
\hline & & & & & & Model & & & MM & MRE & MDM & MRE & PRE & D 0.25 & \\
\hline & & & & & & & $\mathrm{AE}$ & & train & test & train & test & train & test & \\
\hline & & & & & & Euc Dist & $\mathrm{AAl}$ & & 0.96 & 1.25 & 0.51 & 0.58 & 0.33 & 0.19 & \\
\hline & & The Adjusted & & OLS regres- & & & $\operatorname{Imp}$ & & 0.60 & 0.52 & 0.20 & 0.36 & 0.60 & 0.46 & \\
\hline & & Analogy-Based & & sion, artificial & & & $\mathrm{AM}$ & & 38 & 58 & 61 & 38 & 82 & 126 & \\
\hline 14 & $\begin{array}{l}\text { Chiu N, } \\
\text { Huang S }\end{array}$ & $\begin{array}{c}\text { Software Effort } \\
\text { Estimation }\end{array}$ & $\begin{array}{l}\text { The Journal } \\
\text { of Systems and }\end{array}$ & $\begin{array}{c}\text { neural } \\
\text { network }\end{array}$ & DPS database, & Man Dis & AAM & & 1.03 & 1.01 & 0.59 & 0.51 & 0.24 & 0.29 & Cross \\
\hline & $(2007)[34]$ & Based on & Software & CART, case & Abran & & IMP & & 0.66 & 0.49 & 0.26 & 0.31 & 0.52 & 0.38 & Validation \\
\hline & & Similarity & & based reason- & & & $\mathrm{AM}$ & & 36 & 52 & 56 & 39 & 117 & 31 & \\
\hline & & Distances & & ing & & $\begin{array}{c}\text { Minkowsk1 } \\
\text { Dis }\end{array}$ & AAM & & 0.99 & 1.24 & 0.55 & 0.55 & 0.31 & 0.24 & \\
\hline & & & & & & & IMP & & 0.61 & 0.49 & 0.29 & 0.38 & 0.50 & 0.38 & \\
\hline & & & & & & $\begin{array}{l}\text { Mean } \\
\text { imp \% }\end{array}$ & & & 37 & 57 & 55 & 36 & 87 & 72 & \\
\hline
\end{tabular}


Table 1. <Continue>

\begin{tabular}{|c|c|c|c|c|c|c|c|c|c|c|}
\hline \multirow[t]{3}{*}{$\begin{array}{r}\text { Sr } \\
\text { No. }\end{array}$} & Author/Year & Title & $\begin{array}{c}\text { Journal/ } \\
\text { Conference }\end{array}$ & $\begin{array}{l}\text { Approach/ } \\
\text { Technique }\end{array}$ & Datasets & \multicolumn{4}{|c|}{ Performance } & $\begin{array}{l}\text { Testing } \\
\text { Mode }\end{array}$ \\
\hline & \multirow{2}{*}{$\begin{array}{c}\text { Keung J.W, } \\
\text { Kitchenham A } \\
\text { and Jeffery, D } \\
\text { R } \\
(2008)[13]\end{array}$} & \multirow{2}{*}{$\begin{array}{c}\text { Analogy-X: } \\
\text { Providing Statisti- } \\
\text { cal Inference to } \\
\text { Analogy-Based } \\
\text { Software Cost } \\
\text { Estimation }\end{array}$} & \multirow{2}{*}{$\begin{array}{c}\text { IEEE Transac- } \\
\text { tion on Soft- } \\
\text { ware Engineer- } \\
\quad \text { ing }\end{array}$} & \multirow{2}{*}{$\begin{array}{l}\text { Analogy, } \\
\text { Jackknife }\end{array}$} & \multirow[b]{2}{*}{ Desharnais } & \multicolumn{2}{|c|}{ Mental' $\mathbf{R}$} & \multicolumn{2}{|r|}{0.440} & \multirow[b]{2}{*}{ All } \\
\hline & & & & & & \multicolumn{2}{|c|}{ UCL } & \multicolumn{2}{|r|}{0.466} & \\
\hline \multirow{5}{*}{16} & \multirow{5}{*}{$\begin{array}{l}\text { Huang S J, } \\
\text { Chiu N H and } \\
\text { Chen L W, } \\
(2008)[20]\end{array}$} & \multirow{5}{*}{$\begin{array}{c}\text { Integration of } \\
\text { Grey Relational } \\
\text { Analysis with } \\
\text { Genetic Algorithm } \\
\text { for Software Effort } \\
\text { Estimation }\end{array}$} & \multirow{5}{*}{$\begin{array}{c}\text { European } \\
\text { Journal of } \\
\text { Operational } \\
\text { Research, } \\
\text { Elsevier }\end{array}$} & \multirow{5}{*}{$\begin{array}{c}\text { Grey } \\
\text { Relational, } \\
\text { Genetic } \\
\text { Algorithm }\end{array}$} & & & \multicolumn{2}{|c|}{ MMRE } & $\operatorname{Pred}(0.25)$ & \multirow{5}{*}{ Random } \\
\hline & & & & & \multirow{2}{*}{ COCOMO } & $\operatorname{Tr}$ & \multicolumn{2}{|c|}{0.53} & 0.41 & \\
\hline & & & & & & Ts & 20. & & 0.38 & \\
\hline & & & & & \multirow{2}{*}{ Albrecht } & $\operatorname{Tr}$ & 0.3 & & 0.49 & \\
\hline & & & & & & Ts & 0.3 & & 0.48 & \\
\hline \multirow{3}{*}{17} & \multirow{3}{*}{$\begin{array}{l}\text { Kiran et.al., } \\
\text { (2008) }\end{array}$} & \multirow{3}{*}{$\begin{array}{l}\text { Software Devel- } \\
\text { opment Cost } \\
\text { Estimation Using } \\
\text { Wavelet Neural } \\
\text { Networks }\end{array}$} & \multirow{3}{*}{$\begin{array}{c}\text { The Journal of } \\
\text { Systems and } \\
\text { Software }\end{array}$} & & & MMRE & & $\operatorname{ed}(0.25)$ & MdMRE & \\
\hline & & & & $\begin{array}{l}\text { Wavelet } \\
\text { Neural }\end{array}$ & Albrecht & 0.121 & & 0.708 & 0.177 & Random \\
\hline & & & & & Desharnais & 0.198 & & 0.666 & 0.163 & \\
\hline & & Improving Analo- & & Feature & & MMRE & & IdMRE & Pred(25) & \\
\hline 18 & $\begin{array}{c}\text { Azzeh M, } \\
\text { Neagu D, and }\end{array}$ & $\begin{array}{l}\text { gy Software Effort } \\
\text { Estimation Using }\end{array}$ & DDOMUC, & Subset & ISBSG & 28.7 & & 21.8 & 54.7 & Jack \\
\hline 10 & $\begin{array}{l}\text { Cowling P, } \\
(2008)[36]\end{array}$ & $\begin{array}{c}\text { the Fuzzy Feature } \\
\text { Subset Selection } \\
\text { Algorithm }\end{array}$ & FКОVIDE & $\begin{array}{l}\text { Fuzzy } \\
\text { Algorithm }\end{array}$ & Desharnais & 40.2 & & 32.4 & 39.8 & Knifing \\
\hline & & & & & & MMRE & MdMRE & MMER & Pred(0.25) & \\
\hline & & & & & ISBSG & 33.3 & 22.0 & 28.6 & 55.2 & \\
\hline 19 & $\begin{array}{c}\text { Azzeh } \mathrm{M} \text {, } \\
\text { Neagu } \mathrm{D} \text { and }\end{array}$ & $\begin{array}{c}\text { Fuzzy Grey } \\
\text { Relational Analy- }\end{array}$ & Empir Software & $\begin{array}{l}\text { Analogy, } \\
\text { Fuzzy }\end{array}$ & Deshrnais & 30.6 & 17.5 & 34.4 & 64.7 & Jack \\
\hline 19 & Cowling P I, & $\begin{array}{l}\text { sis for Software } \\
\text { fffort Estimation }\end{array}$ & Eng, Springer & $\begin{array}{c}\text { Grey } \\
\text { Relational }\end{array}$ & COCOMO'81 & 23.2 & 14.8 & 25.6 & 66.7 & Knifing \\
\hline & & & & & Kemerer & 36.2 & 33.2 & 34.3 & 52.9 & \\
\hline & & & & & Albrecht & 51.1 & 48.0 & 60.4 & 28.6 & \\
\hline & & & & & & MMRE & & IdMRE & Pred(25) & \\
\hline & & & & & ISBSG & 28.55 & & 17.80 & 59.80 & \\
\hline 20 & $\begin{array}{c}\text { Azzeh } \\
\mathrm{M}, \text {,Neagu D }\end{array}$ & $\begin{array}{l}\text { Analogy-Based } \\
\text { Software Effort }\end{array}$ & The Journal of & Analogy, & COCOMO'81 & 33.37 & & 20.36 & 62.33 & Jack \\
\hline 20 & and Cowling P & $\begin{array}{l}\text { Estimation Using } \\
\text { Fuzzy Numbers }\end{array}$ & Software & Numbers & Desharnais & 26.89 & & 19.32 & 64.94 & Knifing \\
\hline & & & & & Albrecht & 50.08 & & 30.75 & 50.00 & \\
\hline & & & & & Kemerer & 55.65 & & 24.24 & 53.33 & \\
\hline 21 & $\begin{array}{c}\text { Chaudhary K, } \\
(2010)[35]\end{array}$ & $\begin{array}{l}\text { GA Based Optimi- } \\
\text { zation of Software } \\
\text { Development } \\
\text { Effort Estimation }\end{array}$ & IJCSI & \begin{tabular}{|c|} 
SEL \\
model, \\
Walston- \\
Felix \\
model, \\
COCOMO, \\
Genetic \\
Algorithm
\end{tabular} & & & Effort & & & Random \\
\hline & & CPN-A Hybrid & & COCOMO, & & & & $\operatorname{Tr}=19$ & & \\
\hline 22 & $\begin{array}{l}\text {.Hari et. al. } \\
\text { (2011)[37] }\end{array}$ & $\begin{array}{c}\text { Model for Soft- } \\
\text { ware Cost Estima- } \\
\text { tion }\end{array}$ & IEEE Explorer & $\begin{array}{c}\text { PSO, } \\
\text { Neural } \\
\text { Network }\end{array}$ & COCOMO'81 & MARE & & $\mathrm{Ts}=10$ & & Random \\
\hline & & & & & & & MMR & & Pred(25) & \\
\hline & & Predicting Soft- & & & Albr & & 26.1 & & 50 & \\
\hline 23 & Song and & ware Project & Expert System & Analogy, & $\mathrm{COCO}$ & ASA & 24.2 & & 60.3 & 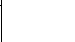 \\
\hline 23 & (2011)[19] & $\begin{array}{l}\text { Relational Analy- } \\
\text { Renal }\end{array}$ & $\begin{array}{c}\text { With Appaca- } \\
\text { tions }\end{array}$ & Numbers & $\mathrm{COCOl}$ & $\mathrm{O}^{\prime} 81$ & 49.8 & & 29 & - \\
\hline & & sis Based Method & & & Desha & hais & 41.4 & & 45.3 & \\
\hline & & & & & Kem & & 19.6 & & 78.6 & \\
\hline
\end{tabular}




\section{Modeling TeCHNIQUES}

\subsection{The Grey Relational Analysis}

This is comparatively a novel technique in software estimations and can be effectively used for analyzing the relationships between two series. It is a technique of the Grey Systems Theory (GST), which was introduced by Deng [1,2,3]. The term Grey lies between Black (meaning "no information") and White (meaning "full information") and it indicates that the information is partially available. It is suitable for unascertained problems with poor information. GRA has the ability to learn from a small number of cases, which is effective in the context of data-starvation [17] The magnetism of GRA is its flexibility to model a complex nonlinear relationship [18,20]. The basic concepts of GRA are as given below:

\section{Factor space:}

$\{p(X) ; Q\}$ is a factor space where $p(X)$ is a theme described by the factor set $X$, and $Q$ as the influence relation. The factor space $\{p(X) ; Q\}$ has the following properties[17]:

1. Existence of key factors.

2. The number of factors is limited and countable.

3. Factor independence.

4. Factor expansibility.

Suppose $x_{i}=\left\{x_{i}(1), x_{i}(2) \ldots, x_{i}(m)\right\}$, where, $i=0,1,2, \ldots, n \in N ; m \in N$, is a data series.

\section{Comparable series:}

The series is comparable if, and only if, they are dimensionless, scaled, and polarized.

\section{Grey relational space:}

The factor space is a grey relational space if all the series in a factor space $\{p(X) ; Q\}$ are comparable. It is denoted as $\{p(X) ; \Gamma\}$. In a grey relational space $\{p(X) ; \Gamma\}, X$ is a collection of data series $x_{i}(i=0,1, \ldots, n)$, in which $x_{i}=\left\{x_{i}(1), x_{i}(2), \ldots, x_{i}(k)\right\}$, is the series; and $k=1,2, \ldots, m$, are the factors. $\Gamma$, which is the Grey Relational Map set. It is based on geometrical mathematics and has the following four properties [17]:

$$
\begin{array}{ll}
\text { Normality } & 0 \leq \Gamma\left(x_{i}(k), x_{j}(k)\right) \leq 1, \forall i, \forall j, \forall k, \\
& \Gamma\left(x_{i}, x_{j}\right)=1 \Leftrightarrow x_{i} \equiv x_{j}, \\
& \Gamma\left(x_{i}, x_{j}\right)=0 \Leftrightarrow x_{i} \cap x_{j} \in \phi .
\end{array}
$$

$$
\begin{array}{cl}
\text { Symmetry } & \forall x_{i}, \forall x_{j} \in X, \\
& \Gamma\left(x_{i}, x_{j}\right)=\Gamma\left(x_{j}, x_{i}\right) \Leftrightarrow X=\left\{x_{i}, x_{j}\right\} . \\
\text { Entirety } \quad \forall x_{i}, \forall x_{j} \in X=\{x \sigma \mid \sigma=0,1, \ldots, n\}, n \geq 2, \\
& \Gamma\left(x_{i}, x_{j}\right) \text { often } \neq \Gamma\left(x_{j}, x_{i}\right) .
\end{array}
$$

Proximity $\quad \Gamma\left(x_{i}(k), x_{j}(k)\right)$ increases as $\Delta(k)=\left|x_{i}(k)-x_{j}(k)\right|$ decrease for $\forall k \in\{1,2, \ldots, m\}$. 


\subsubsection{Grey Relational Grade by Deng's Method}

GRA is used to measure all the influences of various features and the relationship among data series that is a collection of measurements [1-3]. The steps involved are as listed below.

\section{Data Processing}

The first step is the standardization of the various attributes. Every attribute has the same amount of influence, as the data is made dimensionless by using various techniques like upper bound effectiveness, lower bound effectiveness, or moderate effectiveness. The formulas for data processing techniques are as follows:

- Upper-bound effectiveness (i.e., the larger the better)

$$
x_{i}^{*}(k)=\frac{x_{i}(k)-\min _{i} x_{i}(k)}{\max _{i} x_{i}(k)-\min _{i} x_{i}(k)}
$$

where $i=1,2, \ldots, m$ and $k=1,2, \ldots, n$.

- Lower-bound effectiveness (i.e., the smaller the better)

$$
x_{i}^{*}(k)=\frac{\max _{i} x_{i}(k)-x_{i}(k)}{\max _{i} x_{i}(k)-\min _{i} x_{i}(k)}
$$

where $i=1,2, \ldots, m$ and $k=1,2, \ldots, n$.

- Moderate effectiveness (i.e., the nominal is the best)

$$
x_{i}^{*}(k)=1-\frac{\left|x_{i}(k)-x_{a b}(k)\right|}{\max \left\{\max _{i} x_{i}(k)-x_{a b}(k), x_{a b}(k)-\min _{i} x_{i}(k)\right\}}
$$

where $i=1,2, \ldots, m$ and $k=1,2, \ldots, n$.

$x_{i}(k)$ represents the value of the $k_{t h}$ attribute in the $i_{t h}$ series; $(k)$ represents the modified value of the $k_{t h}$ attribute in the $i_{t h}$ series; $\max _{i} x_{i}$ represents the maximum of the $k_{t h}$ attribute in all series; $\min _{i} x_{i}$ represents the minimum of the $k_{t h}$ attribute in all series, and $x_{a b}(k)$ is the objective value of the $k_{t h}$ attribute.

\section{Difference Series}

The GRA uses the grey relational coefficient to describe the trend relationship between an objective series and a reference series at a given point in a system.

$$
\gamma\left(x_{0}(k), x_{i}(k)\right)=\frac{\Delta_{\min }+\zeta \Delta_{\max }}{\Delta_{o, i}(k)+\zeta \Delta_{\max }}
$$


where $\Delta_{0, i}(k)=\left|x_{0}(k)-x_{i}(k)\right|$ is the difference of the absolute value between $x_{0}(k)$ and $x_{i}(k)$;

$\Delta_{\text {min }}=\min _{j} \min _{k}\left|x_{0}(k)-x_{j}(k)\right|$ is the smallest value of $\Delta_{0, j} \forall j \in\left\{1,2, \ldots, n_{\}}\right.$;

$\Delta_{\text {max }}=\max _{j} \max _{k}\left|x_{0}(k)-x_{j}(k)\right|$ is the largest value of $\Delta_{0, j} \forall j \in\left\{1,2, \ldots, n_{j}\right.$;

and $\zeta$ is the distinguishing coefficient, $\zeta \in(0,1]$.

The $\zeta$ value will change the magnitude of $\gamma\left(x_{0}(k), x_{i}(k)\right.$. In this study the value of $\zeta$ has been taken as 0.5 Deng [23].

\section{Grey Relational Grade}

The GRG is used to find the overall similarity degree between reference tuple $x_{o}$ and comparative tuple $x_{i}$. When the value of the GRG approaches 1, the two tuples are "more closely similar." When the GRG approaches a value of 0 , the two tuples are "more dissimilar." The GRG $\Gamma\left(x_{0}, x_{i}\right)$ between an objective series $x_{i}$ and the reference series $x_{0}$ was defined by Deng as follows:

$$
\Gamma\left(x_{0}, x_{i}\right)=\frac{1}{n} \sum_{k=1}^{n} \gamma\left(x_{0}(k), x_{i}(k)\right)
$$

\subsection{Regression}

Regression analysis is a statistical technique for modelling and analysing variables. It is used to study the relationship that exists between a dependent variable and one or more independent variables.

\subsubsection{Ordinary Least Square Regression}

It is the most popular and widely applied technique to build software cost estimation models. According to the principle of least squares the "best fitting" line is the line which minimizes the deviations of the observed data away from the line. The regression parameters for the least square line, are the estimates of the unknown regression parameters in the model. This is also referred to as multiple linear regression and is given by:

$$
y_{i}=\beta_{0}+\beta_{1} x_{i, 1}+\ldots . . \beta_{k} x_{i, k}+\varepsilon_{i}
$$

where, $Y_{\mathrm{i}}$ is a dependent variable whereas $x_{1,}, x_{2}, \ldots \ldots x_{k}$ are $k$ independent variables. $\beta_{o}$ is the $y$ intercept, $\beta_{1}, \beta_{2}$ are the slope of $y, \varepsilon_{i}$ is the error term. The corresponding prediction equation is given as:

$$
\hat{y}_{i}=\hat{\beta}_{0}+\hat{\beta}_{1} x_{i, 1}+\ldots . \hat{\beta}_{k} x_{i, k}
$$

In this equation $\hat{\beta}_{0}, \hat{\beta}_{1}, \ldots \ldots \ldots \hat{\beta}_{k}$ are the least square coefficients and $\hat{y}_{i}$ is the estimated response for the $i^{\text {th }}$ term.

Thus, the response estimated from the regression line minimizes the sum of squared distances between the regression line and the observed response. 


\subsubsection{Robust Regression}

Robust Regression is a type of regression technique, which prevails over the limitations of the ordinary least square. Ordinary least square estimates are extremely non-robust to outliers. Outliers are those observations in the dataset that do not follow the prototype of the other observations. These can inefficiently influence the whole process of fitting. In this study, we evaluated the performance of some well-known robust M-estimators. They are as follows: the "Andrewestimator" [40], the "Bisquare-estimator," the "Cauchy-estimator," the "Fair-estimator," the "Huber-estimator" [38, 39, 43], the "Logistic-estimator," the "Talwar-estimator," and the "Welsch-estimator," etc. They have been used with their different weight functions [41] for predicting the software effort of the projects.

M-estimators are also called maximum-likelihood estimators, as they try to minimize the weighted sum of residuals. They work on the principle of the Iteratively Reweighted Least Square (IRLS). The least square method tries to minimize $\sum e_{i}{ }_{i}$, which is unstable in case there are outliers present in the data, whereas the M-estimators try to minimize the effect of these outliers by substituting the squared residuals $\mathrm{e}_{\mathrm{i}}$, by the function given below.

$$
\min \sum_{i=1}^{n} \rho\left(e_{i}\right)
$$

The steps involved in IRLS [42] are:

Step 1: In the first iteration, each observation is allocated an equal weight and the coefficients of the model are estimated using OLS.

Step 2: In the second step, after the OLS, residuals are used to find weights. The observation with a larger residual is assigned a lower weight.

Step 3: In the third iteration, the new model parameters and the residuals are recomputed using Weighted Least Squares (WLS).

Step 4: In Step 4, new weights, as per Step 2, are found and the procedure continues until the values of the parameter estimates converge within a specified tolerance.

\subsubsection{Stepwise Regression}

This is a method for adding and removing terms based on their statistical importance. The forward approach starts with no variables in the model. It tries out the variables one by one and includes them if they are "statistically important." The selection has been used for estimating the effort of the reference project for various similar projects. At each step, a predictor is entered based on partial $F$-tests or $t$ test. The procedure continues until more variables can be justifiably entered. The first variable that is put in the stepwise model is the variable having the smallest $t$ test $P$-value (below $\alpha_{\mathrm{E}}=0.05$ ). The level of significance $(\alpha)$ is taken to be $5 \%$.

\section{Proposed Algorithm, for Software Estimation}

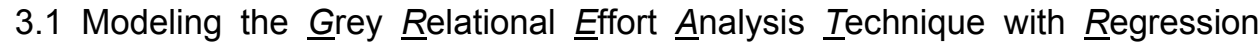 Methods (GREAT_RM)}

In this methodology, the focus is project selection based on GRA and effort prediction by re- 
gression. In the GRA based studies so far, effort is estimated by generating similar projects to the target project and then estimating effort from those most similar projects. GREAT_RM uses GRA for generating similar projects to the target project, but effort is calculated by applying regression on those most similar projects. In this study, ten regression techniques have been applied, including OLS, eight robust regression methods, and SWR. The individuality of the work is that the value of $k$ varies with each reference project. The basic steps of the methodology are:

Step 1: Select the continuous attributes from the dataset.

Step2: Data series construction: The data set consists of series $\mathrm{x}_{0}=\left\{\mathrm{x}_{1}(1), \mathrm{x}_{1}(2), \ldots, \mathrm{x}_{1}(\mathrm{~m})\right\}$, $\mathrm{x}_{1}=\left\{\mathrm{x}_{2}(1), \mathrm{x}_{2}(2), \ldots, \mathrm{x}_{2}(\mathrm{~m})\right\}, \mathrm{x}_{2}=\left\{\mathrm{x}_{3}(1), \mathrm{x}_{3}(2), \ldots, \mathrm{x}_{3}(\mathrm{~m})\right\}$ and $\mathrm{x}_{\mathrm{n}}=\left\{\mathrm{x}_{\mathrm{n}}(1), \mathrm{x}_{\mathrm{n}}(2), \ldots, \mathrm{x}_{\mathrm{n}}(\mathrm{m})\right\}, \mathrm{x}_{0}$ is the reference series whose effort is to be estimated based on the objective series $\mathrm{x}_{1}$, $\mathrm{x}_{2}, \ldots \mathrm{x}_{\mathrm{n}}$.

Step3: Data Preparation: The numerical features are normalized in a specified range so that each feature has the same weight on effort and hence it eases out their comparisons and processing.

Step4: Ranking the $k$ closest projects: This aims at retrieving software projects from the data that exhibits large similarities with projects that are under investigation. The distance $\bar{\Delta}_{o, i}$ between two tuples at the $k^{\text {th }}$ feature, is calculated by the formula as shown in Eq. (4).

$$
\gamma\left(x_{0}(k), x_{i}(k)\right)=\frac{\Delta_{\min }+\zeta \Delta_{\max }}{\Delta_{o, i}(k)+\zeta \Delta_{\max }}
$$

For all grey relational grades between the reference project $o$ and the $i^{\text {th }}$ comparative project, the $\Gamma\left(x_{o}, x_{i}\right)$ values are calculated for each $i$ according to Eq. (5). The range of $\Gamma$ is from 0 to 1 in each case [47]. For more similarity between projects the value of $\Gamma$ approaches one and for two projects that are completely dissimilar, it approaches zero. The projects that have the higher value on GRG get the greatest opportunity to contribute in the final estimate.

Step5. Effort Prediction by GRA: The effort for GRA is the simple aggregation of the $k$ most influential projects [17].

$$
\hat{\varepsilon}=\sum_{i=1}^{k} w_{i} * \varepsilon_{i}
$$

where, $\varepsilon_{\mathrm{i}}$ is the effort of the $i^{\text {th }}$ most influential project and $w_{i}$ is the weight given by:

$$
w_{i}=\frac{\tau\left(x_{0}, x_{i}\right)}{\sum_{j=1}^{k} \tau\left(x_{0}, x_{i}\right)}
$$

Step 6. Effort Prediction by Regression: In this step, effort estimate for a given project is cal- 
culated by applying various regression techniques on only the $k$ most similar projects obtained from Step 4.

\subsection{Evaluation criteria}

For the purpose of validating and evaluating the new methodology, the basic necessity is to measure how accurate the estimations are. There are various approaches used by researchers to measure the accuracy of effort prediction methods, such as the Mean Magnitude of Relative Error (MMRE), the Median Magnitude of Relative Error (MdMRE), the Magnitude of Relative Error Relative to the Estimate (MMER), the adjusted R-squared or coefficient of determination, and $\operatorname{Pred}(n)$. In order to measure the accuracy of the software estimation, we have used the four most popularly used evaluation criteria in software engineering, (i.e., MMRE, MdMRE, MMER and $\operatorname{Pred}(n)$.)

\subsubsection{Mean Magnitude of Relative Error (MMRE)}

Relative error is the absolute error in the observations divided by its actual value. The magnitude of relative error is the percentage of actual effort for the project and is given as:

$$
M R E=\frac{\mid \text { actual }- \text { estimated } \mid}{\text { actual }}
$$

The MRE for each observation is aggregated over the total number of projects, N, in order to generate the mean MRE (MMRE). MMRE is calculated as:

$$
M M R E=\frac{1}{N} \sum_{X=1}^{N} M R E_{x}
$$

MMRE favors models that underestimate, and it is extremely sensitive to small actuals. As MMRE is sensitive to individual predictions with excessively large MREs, we also use the median of MRE's for the $\mathrm{n}$ projects. (MdMRE), which is less sensitive to extreme values, is used as another measure for estimation accuracy.

\subsubsection{Median MRE (MdMRE)}

Median MRE is less sensitive to extreme values as compared to MMRE, so in case of large datasets we prefer using MdMRE as the estimation accuracy criteria and it is given by:

$$
M d M R E=\text { median }(M R E x)
$$

A higher score for both MMRE and MdMRE means worse prediction accuracy.

\subsubsection{Magnitude of Relative Error relative to the Estimate (MMER):}

Another measure akin to MRE is MER. It is more preferable to MRE since it measures the error relative to the estimate. MER is given by: 


$$
M E R=\frac{\mid \text { actual }_{i}-\text { estimated }_{i} \mid}{\text { estimated }_{i}}
$$

We use the notation MMER to denote the mean MER.

$$
M M E R=\frac{1}{N} \sum_{X=1}^{N} M E R_{x}
$$

\subsubsection{Pred (n)}

It is used as the opposite measure to count the percentage of estimates that fall within less than $n$ percent of the actual values. The common used value for Pred(n) is $25 \%$. A low score on MMRE, MdMRE, MMER and a high score on Pred (n) entails better accuracy.

\subsection{Data Sources}

The data used in the present study comes from the PROMISE repository [44]. Though these datasets are old, they are still extensively being used to assess the comparative accuracy of new techniques. The descriptive statistics of these sets are given below. Five different datasets have been used in the study with the belief that if the model validation is successful with these models then it can also be validated on any other dataset. The descriptive statistics of all the five dataset are given below in Table 2 .

Table 2. Descriptive Statistics of the Datasets

\begin{tabular}{c|c|c|c|c|c}
\hline & Dataset & Cases & Features & Effort Mean & Effort Standard Deviation \\
\hline 1. & Finnish & 38 & 8 & $7,678.29$ & $7,135.28$ (hours) \\
\hline 2. & Desharnais & 77 & 9 & 4,834 & 4,188 (hours) \\
\hline 3. & COCOMO-81 & 63 & 17 & 683.52 & $1,821.51$ (hours) \\
\hline 4. & Albrecht & 24 & 8 & 21,875 & 28,417 (hours) \\
\hline 5. & Kemerer & 15 & 5 & 219.25 & 263 (man hours) \\
\hline
\end{tabular}

\section{EXPERIMENTAL RESULTS}

The results obtained using the proposed methods are summarized in Table 3. The table provides the comparison of results obtained using only GRA, GRA and OLS, GRA and RR, and finally GRA and SWR for all of the five datasets. Only the best result obtained using eight robust regression techniques have been produced and put to statistical analysis. This empirical study is carried out using Leave One Out Cross Validation (LOOCV). For each iteration, one project is held out once and the training is performed on (n-1) projects. The accuracy is then measured by aggregating the accuracy of all the sets.

Boxplot of absolute residuals and Wilcoxon signed rank test of residuals are applied in order to study the distribution of residuals and statistical significance of GREAT_RM technique. 
Table 3. Prediction Accuracy Results of GREAT_RM

\begin{tabular}{|c|c|c|c|c|}
\hline & GRA & GRA with OLS & $\begin{array}{c}\text { GRA with } \\
\text { Robust Regression }\end{array}$ & $\begin{array}{l}\text { GRA with } \\
\text { Stepwise }\end{array}$ \\
\hline \multicolumn{5}{|c|}{ Finnish dataset } \\
\hline MMRE & 11.37 & 11.88 & 10.3 & 58.61 \\
\hline Median (MRE) & 2.67 & 2.19 & 1.93 & 27.93 \\
\hline MMER & 12 & 12.88 & 9.81 & 40.99 \\
\hline Pred (25) & 76.32 & 89.47 & 89.47 & 47.37 \\
\hline \multicolumn{5}{|c|}{ Albrecht dataset } \\
\hline MMRE & 46.35 & 29.83 & 24.16 & 32.64 \\
\hline Median (MRE) & 4.89 & 7.47 & 10 & 12.39 \\
\hline MMER & 17.15 & 21.72 & 22.57 & 24.87 \\
\hline Pred (25) & 70.83 & 70.83 & 70.83 & 70.83 \\
\hline \multicolumn{5}{|c|}{ COСОМО -81 dataset } \\
\hline MMRE & 30 & 32.35 & 25.59 & 21.04 \\
\hline Median (MRE) & 7.07 & 5.32 & 4.82 & 9.42 \\
\hline MMER & 26.86 & 15.71 & 18.9 & 48.71 \\
\hline Pred (25) & 68.25 & 76.19 & 74.6 & 76.19 \\
\hline \multicolumn{5}{|c|}{ Desharnais dataset } \\
\hline MMRE & 34.9 & 18.19 & 25.44 & 16.78 \\
\hline Median (MRE) & 5.07 & 1.51 & 8.36 & 7.84 \\
\hline MMER & 22.12 & 8.74 & 18.97 & 31.63 \\
\hline Pred (25) & 68.83 & 90.9 & 79.22 & 74.02 \\
\hline \multicolumn{5}{|c|}{ Kemerer dataset } \\
\hline MMRE & 46.67 & 35.18 & 29.63 & 38.65 \\
\hline Median(MRE) & 11.46 & 21.92 & 16.56 & 31.35 \\
\hline MMER & 35.58 & 41.04 & 27.93 & 78.8 \\
\hline Pred (25) & 60 & 53.33 & 60 & 40 \\
\hline
\end{tabular}

Boxplots represent the results obtained by GRA, GRA+OLS, GRA+RR, and GRA+SWR.

1. The Boxplots in Fig. 1,2,3,4, and 5 show that medians are very close to zero for all the datasets, thus indicating that the spread is tighter towards the minimum value. The box overlays the lower tail for Albrecht, COCOMO-81, Desharnais, and Kemerer datasets, thus presenting an accurate prediction.

2. The range of absolute residuals for the Finnish dataset is large for GRA and GRA+SWR, but because the medians are tilted towards the minimum value, it indicates that the predictions are good. 


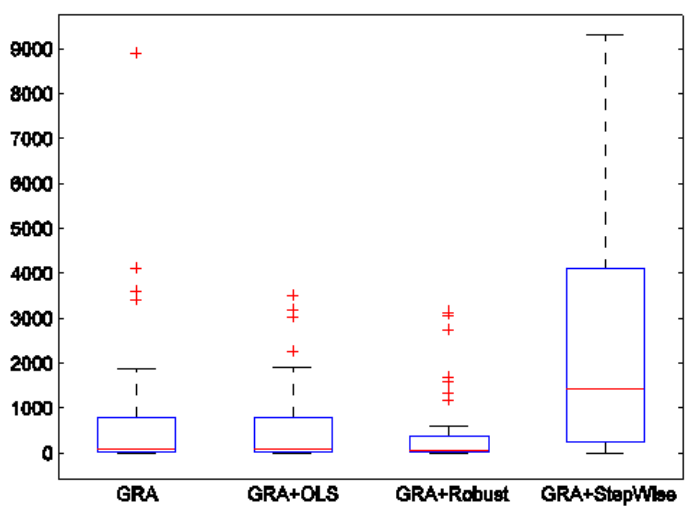

Fig. 1. Boxplot of Absolute Residuals for the Finnish dataset

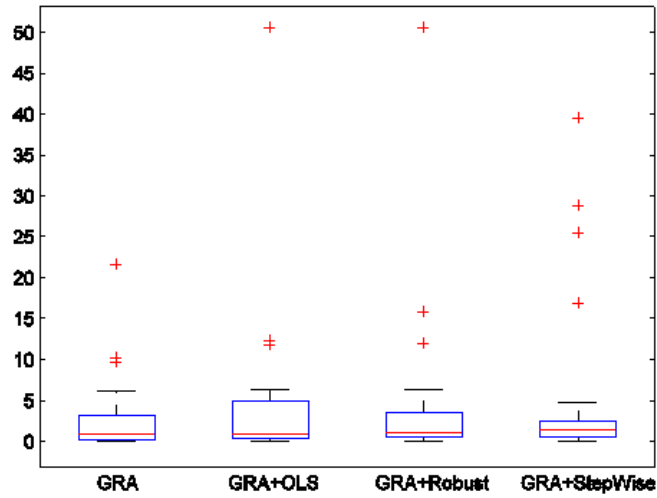

Fig. 2. Boxplot of Absolute Residuals for the Albrecht dataset

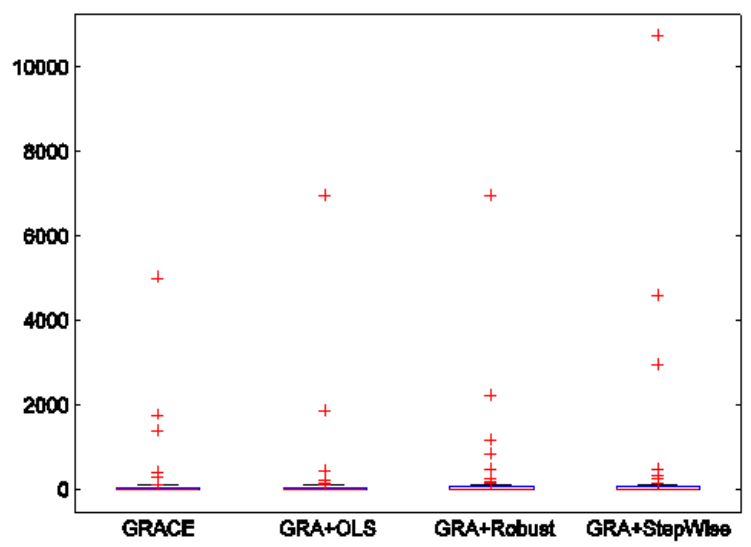

Fig. 3. Boxplot of Absolute Residuals for the COCOMO-81 dataset 


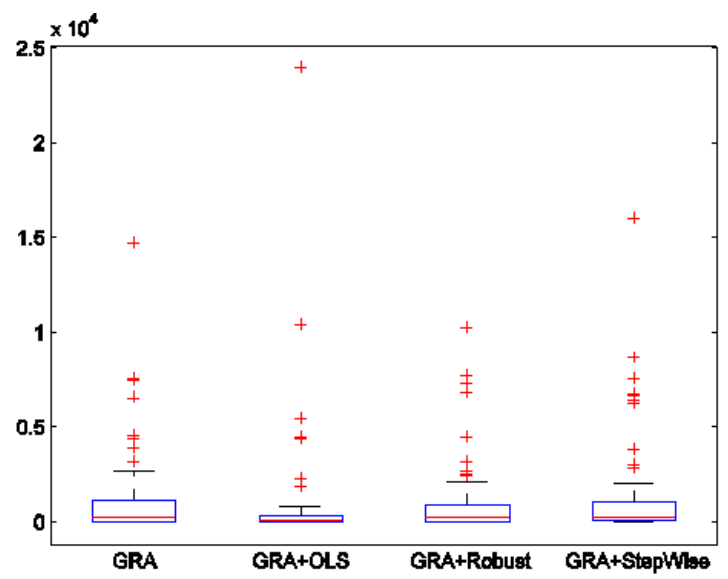

Fig. 4. Boxplot of Absolute Residuals for the Desharnais dataset

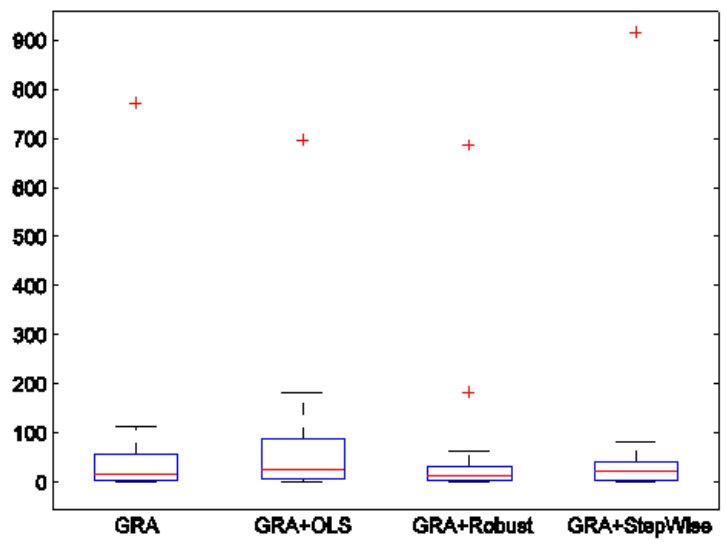

Fig. 5. Boxplot of Absolute Residuals for the Kemerer Dataset

\subsection{Comparison of GREAT_RM to Multiple Linear Regression, Ridge Regression, Neural Networks, Support Vector Machine, and Multiple Adaptive Regression Splines}

This section presents the results obtained when we compared the GREAT_RM model to Multiple Linear Regression (MLR), Ridge Regression (RR), Artificial Neural Networks (ANN), the Support Vector Machine (SVM), and Multiple Adaptive Regression Splines (MARS). We should note here that all the techniques were applied to the same numerical features of the same five datasets. However, in this section we investigate whether these techniques produce equivalent or better results than GREAT_RM. We used boxplots of absolute residuals to statistically measure the distribution of residuals. Based on absolute residuals we tested the statistical significance of all the results. All statistical significant tests were obtained using SPSS 19 for Windows. 
(1) Multiple Linear Regression (MLR): In this work, the MLR uses data collected from historical projects to examine the relationships between independent attributes and dependent attributes and then developed a formal model based on that. This is already explained in Section 2.2.1

(2) Artificial Neural Network (ANN): ANNs are very sophisticated modeling and prediction techniques that are capable of modeling extremely complex functions and data relationships. They have the ability to learn by examples, which enables the user to model data and establish accurate rules governing the underlying relationship between various data attributes. They take the sample data, and then invoke training algorithms, which can automatically learn the structure of the data. One of the abilities of the neural network is to accurately predict data that is not part of the training dataset, and the process is known as generalization. In this work, multilayer perceptrons have been applied. Multilayer perceptrons are supervised feed-forward networks trained with a back propagation algorithm. With training input data and preferred output data, the multilayer perceptrons are trained on how to convert input data into a particular output. Three parameters have a major impact on the accuracy of the network, which should be defined before building the network. They are: number of hidden layers, the number of neurons in each hidden layer, and the type of activation functions [23].

(3) Ridge Regression (RR): $\mathrm{RR}$ is an alternative regression technique that tries to address the potential problems with OLS that arise due to highly correlated attributes. In regression, the objective is to "explain" the variation in one or more "response variables," by associating this variation with proportional variation in one or more "explanatory variables. However, the problem arises when the explanatory variables vary in similar ways, which reduces their collective power of explanation. This phenomenon is known as near collinearity. As the different variables are correlated the covariance matrix $\mathrm{X}^{\prime} \mathrm{X}$ will be nearly singular and as a result the estimates will be unstable. A small variation in error will have a large impact on $\widehat{\beta}$. Ridge regression reduces the sensitivity by adding a number $\delta$ to the elements on the diagonal of the matrix that is to be inverted. $\delta$ is called the ridge parameter and it yields the following estimator of $\beta$.

$$
\hat{\beta}_{\delta}=\left(X^{\prime} X+\delta I_{n}\right)^{-1}\left(X^{\prime} e\right)
$$

where, $I_{n}$ represents the identity matrix of rank $\mathrm{n}$.

(4) Support Vector Machine (SVM): The regression SVM estimates the functional dependence of the dependent variable $y$ on a set of independent variables $x$. It assumes, like other regression problems, that the relationship between the independent and dependent variables is given by a deterministic function of $f$ plus the addition of some additive noise.

$$
y=f(x)+\text { noise }
$$

SVM finds a functional form for $f$ that correctly predicts new cases that are presented to SVM. This is achieved by training the SVM model on a sample set (i.e., training set, a process that involves the sequential optimization of an error function). SVM constructs a hyper plane or set of hyper planes in a high- or infinite-dimensional space, which can be used for regression. A 
good separation is achieved by the hyper plane that has the largest distance to the nearest training data point of any class. In general, the larger the margin, the lower the generalization error of the classifier. To construct an optimal hyper plane, SVM employs an iterative training algorithm, which minimizes an error function.

(5) MAR Splines: MAR Splines focuses on the development and deployment of accurate and easy-to-understand regression models. The MAR Splines model is designed to predict continuous numeric and high quality probability models. The MAR Splines model is a regression model that automatically generates non-linearities and interactions between variables and is thus a promising technique to be used for software effort estimation. MAR Splines has shown evidences of very high-performance results in forecasting the electricity requirement for powergenerating companies, relating customer satisfaction scores to the engineering specifications of products, and presence/absence modeling in Geographical Information Systems (GIS). MAR Splines fits the data in the following equation:

$$
e_{i}=b_{0}+\sum_{k=1}^{K} b_{k} \Pi_{i=1}^{L} h_{i}\left(x_{i}(j)\right)
$$

In this $b_{o}$ and $b_{k}$ are the intercept and slope. Parameters $h_{i}\left(x_{i}(j)\right)$ are the hinge functions. They take the form $\max \left(0, x_{i}(j)-b\right)$ where, $b$ is the knot. MAR Splines behaves as a multiple piece wise linear regression by adding multiple hinge functions.

\subsection{Comparison of the Finnish Dataset}

Table 4 summarizes the accuracy of the respective methods when applied to the Finnish data. From the results we can observe that GREAT_RM produced better accuracy than all other models.

The results also revealed that GREAT_RM, ANN, and MAR Splines are similar in terms of MMRE, MdMRE, and Pred (25) accuracy. The Boxplot of absolute residuals for the various techniques shows that:

- The box of GREAT_RM overlays the lower tail, which implies that the absolute residuals are skewed towards the minimum value and that it also presents a more accurate estimation than all other models.

- The median of GREAT_RM is smaller than the median of other models, which revealed that at least half of the predictions are more accurate than other models.

Table 4. Results of the Finnish Dataset

\begin{tabular}{l|c|c|c|c|c|c}
\hline & OLS & RR & ANN & SVM & MAR Splines & GREAT_RM \\
\hline MMRE & 0.75 & 0.71 & 0.06 & 0.42 & 0.08 & 0.103 \\
\hline MdMRE & 0.36 & 0.32 & 0.02 & 0.16 & 0.07 & 0.193 \\
\hline MMER & 0.05 & 1.3 & 0.05 & 0.13 & 0.09 & 0.981 \\
\hline Pred (25) & 36.84 & 36.84 & 92.11 & 63.15 & 97.37 & 89.47 \\
\hline
\end{tabular}




\section{Finnish}

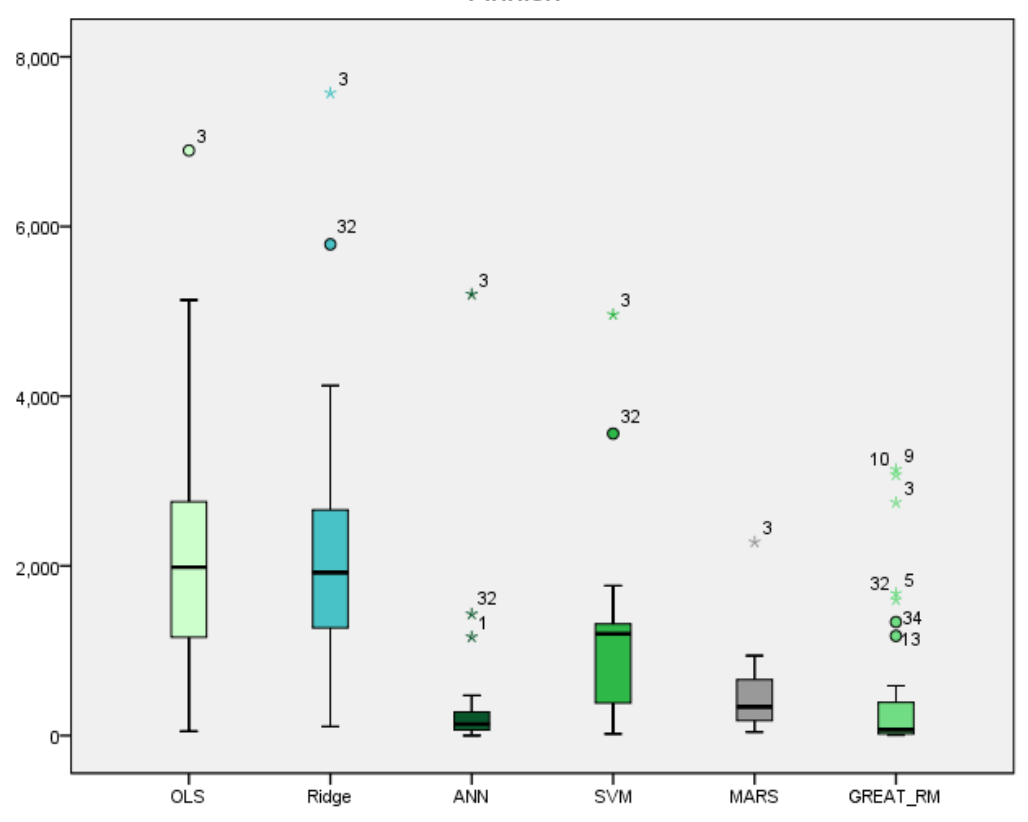

Fig. 6. Boxplot of Absolute Residuals for Finnish data set

\section{Finnish}

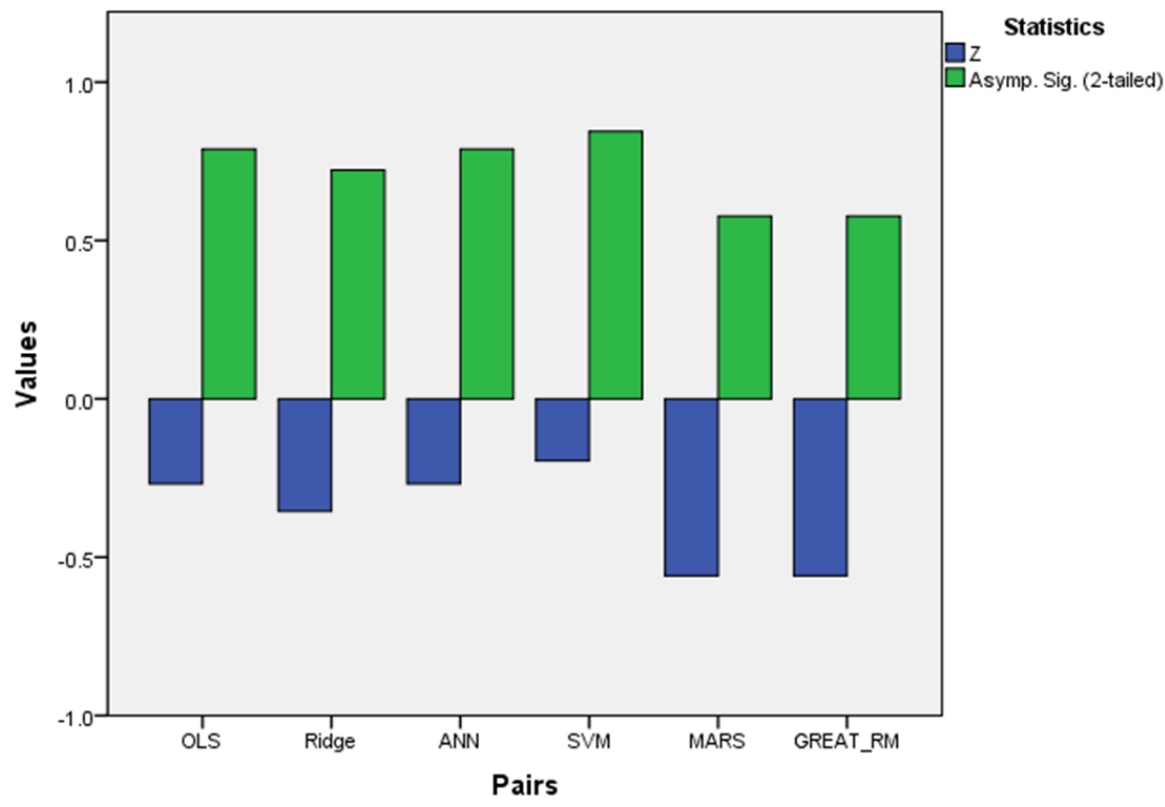

Fig. 7. Bar Graph(WILCOXON Signed Rank Test) 
Table 5. Wilcoxon signed rank test $\left(\right.$ Test Statistics $\left.^{\mathrm{c}}\right)$

\begin{tabular}{c|c|c|c|c|c|c}
\hline Finnish Dataset & OLS & Ridge & ANN & SVM & MARS & GREAT_RM \\
\hline Z & $-.268^{\mathrm{a}}$ & $-.355^{\mathrm{a}}$ & $-.268^{\mathrm{b}}$ & $-.196^{\mathrm{b}}$ & $-.558^{\mathrm{a}}$ & $-.558^{\mathrm{a}}$ \\
\hline Asymp. Sig. (2-tailed) & .788 & .722 & .788 & .845 & .577 & .577 \\
\hline
\end{tabular}

\section{WILCOXON Signed Rank Test:}

Step 1: Hypotheses

$$
\begin{aligned}
& H_{0}: \mu(\text { Before })=\mu(\text { After }) ; H_{a}: \mu(\text { Before })>\mu(\text { After }) \\
& \text { (Residual Median) }=\text { Hypothetical Median (test value) } .
\end{aligned}
$$

Step 2: Significance Level: $\alpha=0.05$.

Step 3: Rejection Region: Reject the null hypothesis if $\mathrm{p}$-value $<=0.05$.

Step 4: Test Statistic: Wilcoxon signed rank test.

Step 5: Decision.

The p-value in all the cases is greater than 0.05 , as shown in Table 5. Thus, we accept the null hypothesis. Consequently, we conclude that the residuals obtained by using all approaches were not significantly different from the test value of zero. As a result, the proposed methods can be used for software effort estimation.

\subsection{Comparison of the Albrecht Dataset}

On analyzing the Albrecht results, Table 6 summarizes the accuracy of the respective methods. From the results we can observe that GREAT_RM produced better accuracy than OLS, ridge, ANN, SVM, and MAR Splines.

The results also revealed that GREAT_RM produced better results of not only MMRE, but also MdMRE, MMER, and Pred (25). Thus, GREAT_RM tends to be more accurate than all other models. Amongst the other models, ANN produced better results in the Albrecht dataset. Unsurprisingly, predictions based on the GREAT_RM model presented statistically significant accurate estimations, which was also established by the Boxplot of absolute residuals as shown in Fig. 8.

The Boxplot of absolute residuals for the various techniques shows that:

- The box of GREAT_RM overlays the lower tail, which shows that the absolute residuals are skewed towards the minimum value and also presents an accurate estimation.

- The range of absolute residuals of GREAT_RM and ANN are smaller than the absolute residuals of other models, which implies that the variance is less.

Table 6. Results of the Albrecht Dataset

\begin{tabular}{c|c|c|c|c|c|c}
\hline & OLS & RR & ANN & SVM & MAR Splines & GREAT_RM \\
\hline \multicolumn{7}{c}{ Albrecht Dataset } \\
\hline MMRE & 0.9 & 0.91 & 0.78 & 0.51 & 1.23 & 0.24 \\
\hline MdMRE & 0.43 & 0.52 & 0.17 & 0.33 & 0.6 & 0.10 \\
\hline MMER & 0.17 & 0.27 & 0.28 & 0.35 & 0.52 & 0.23 \\
\hline Pred (25) & 37.5 & 37.5 & 58.33 & 45.83 & 29.17 & 70.83 \\
\hline
\end{tabular}




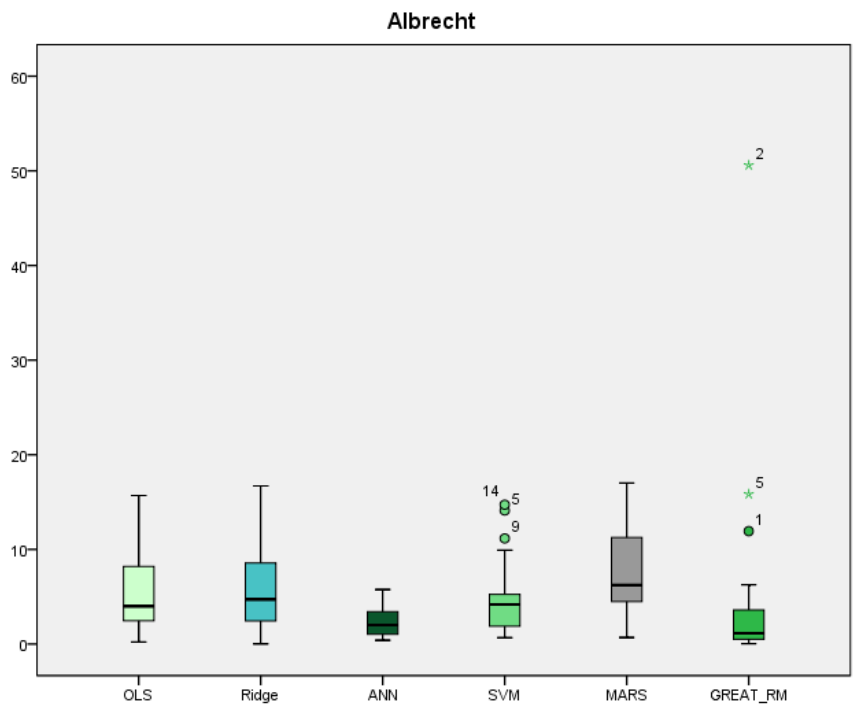

Fig. 8. Boxplot of Absolute Residuals for Albrecht data set

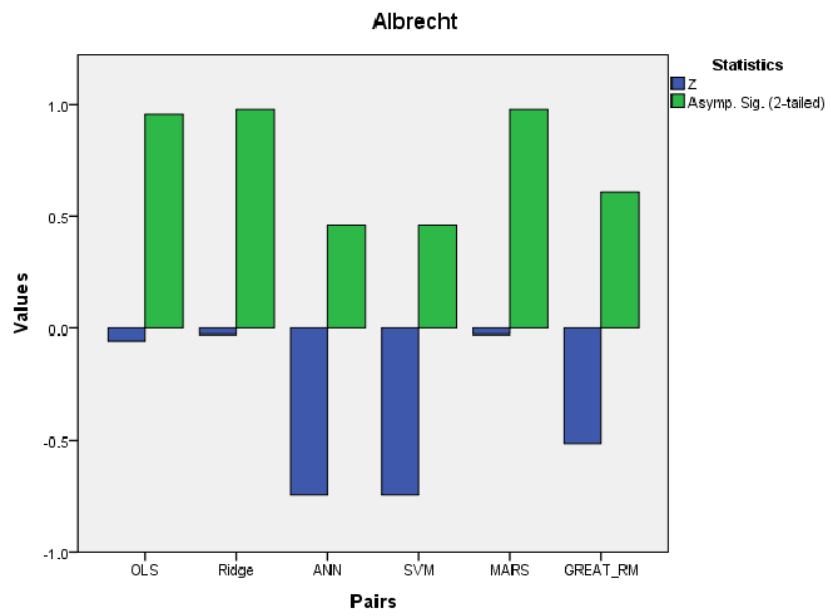

Fig. 9. Bar Graph (WILCOXON Signed Rank Test)

- The median of GREAT_RM is smaller than the median of other models, which revealed that at least half of the predictions of FGRA are more accurate than other models.

\section{WILCOXON Signed Rank Test:}

The p-value in all the cases is greater than 0.05, as shown in Table 7. Thus, we accept the null hypothesis. Consequently, we conclude that the residuals obtained by using all approaches were not significantly different from the test value of zero. As a result, the proposed methods can be used for software effort estimation. 
Table 7. Wilcoxon signed rank test $\left(\right.$ Test Statistics $\left.^{\mathrm{c}}\right)$

\begin{tabular}{c|c|c|c|c|c|c}
\hline Albrecht Dataset & OLS & Ridge & ANN & SVM & MARS & GREAT_RM \\
\hline Z & $-.057^{\mathrm{a}}$ & $-.029^{\mathrm{a}}$ & $-.743^{\mathrm{a}}$ & $-.743^{\mathrm{b}}$ & $-.029^{\mathrm{b}}$ & $-.514^{\mathrm{a}}$ \\
\hline Asymp. Sig. (2-tailed) & .954 & .977 & .458 & .458 & .977 & .607 \\
\hline
\end{tabular}

\subsection{Comparison of the COCOMO-81 Dataset}

Table 8 summarizes the accuracy of the various models in the COCOMO_81 dataset. From the results we can observe that GREAT_RM performed significantly better than all of the other models. The results also revealed that GREAT_RM produced credible results in terms of not only MMRE but also MdMRE, MMER, and Pred (25).

The Boxplot of absolute residuals for the various techniques shows that:

Predictions based on the GREAT_RM model presented statistically significant accurate estimations, measured using absolute residuals, and was confirmed by the results of the Boxplot of absolute residuals, as shown in Fig. 10.

- The box of GREAT_RM has been minimized as can be seen in Fig. 10, which shows that

Table 8. Results of the COCOMO_81 Dataset

\begin{tabular}{c|c|c|c|c|c|c}
\hline & OLS & RR & ANN & SVM & MAR Splines & GREAT_RM \\
\hline \multicolumn{7}{c}{ COCOMO-81 Dataset } \\
\hline MMRE & 14.77 & 12.73 & 2.67 & 11.25 & 16.79 & 0.25 \\
\hline MdMRE & 3.72 & 3.56 & 0.88 & 2.39 & 2.73 & 0.482 \\
\hline MMER & 0.33 & 0.52 & 1.77 & 0.18 & 15.87 & 0.189 \\
\hline Pred (25) & 11.11 & 12.69 & 25.39 & 12.69 & 0.02 & 74.6 \\
\hline
\end{tabular}

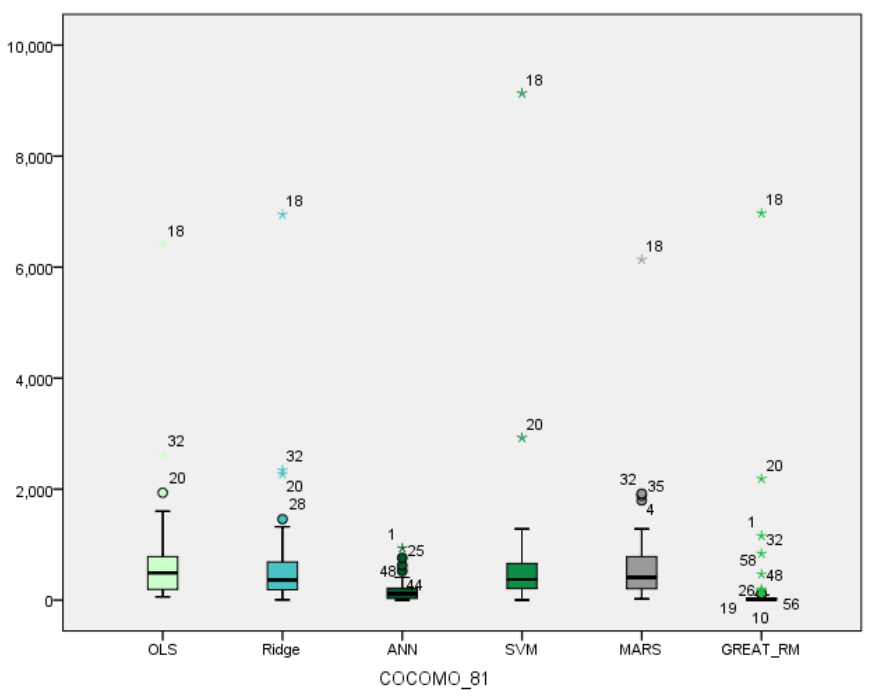

Fig. 10. Boxplot of Absolute Residuals for the COCOMO_81 Dataset 


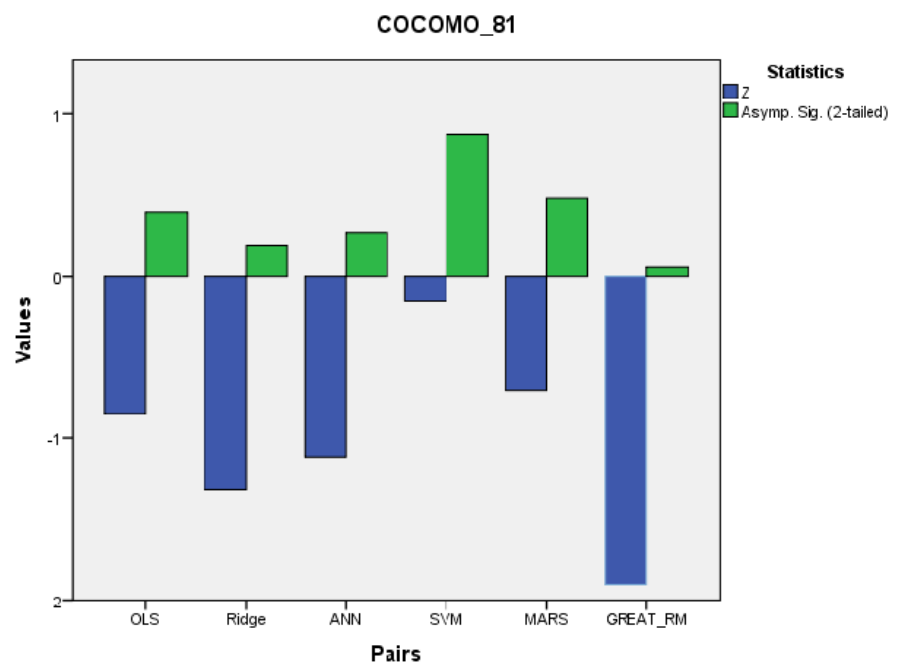

Fig. 11. Bar Graph (WILCOXON Signed Rank Test)

Table 9. Wilcoxon signed rank test (Test Statistics)

\begin{tabular}{c|c|c|c|c|c|c}
\hline COCOMO_81 Dataset & OLS & Ridge & ANN & SVM & MARS & GREAT_RM \\
\hline Z & $-.849^{\mathrm{a}}$ & $-1.321^{\mathrm{a}}$ & $-1.116^{\mathrm{a}}$ & $-.157^{\mathrm{a}}$ & $-.705^{\mathrm{a}}$ & $-1.903^{\mathrm{a}}$ \\
\hline Asymp. Sig. (2-tailed) & .396 & .186 & .264 & .875 & .481 & .057 \\
\hline
\end{tabular}

a. Based on positive ranks. b. Wilcoxon signed rank test

the absolute residuals are skewed towards the minimum value and thus presents a more accurate estimation than the other five models.

- The range of absolute residuals of GREAT_RM is smaller than the absolute residuals of others.

- The median of GREAT_RM is approaching zero, which revealed that at least half of the predictions of FGRA are more accurate than other models.

- On the other hand, the range of absolute residual values for OLS, Ridge, SVM, and MARS produced the worst individual estimation.

\section{WILCOXON Signed Rank Test:}

The p-value in all the cases is greater than 0.05, as shown in Table 9. Thus, we accept the null hypothesis. Consequently, we conclude that the residuals obtained by using all approaches are not significantly different from the test value of zero. As a result, all the proposed methods can be used for software effort estimation.

\subsection{Comparison of the Desharnais Dataset}

Table 10 summarizes the accuracy of the various models in the Desharnais dataset. From the results we can observe that GREAT_RM performed significantly better than all of the other models. The results also revealed that GREAT_RM produced credible results in terms of not 
Table 10. Wilcoxon Signed Rank Test

\begin{tabular}{c|c|c|c|c|c|c}
\hline & OLS & RR & ANN & SVM & MAR Splines & GREAT_RM \\
\hline \multicolumn{7}{c}{ Desharnais Dataset } \\
\hline MMRE & 0.5 & 0.47 & 0.47 & 0.48 & 0.51 & 0.16 \\
\hline MdMRE & 0.31 & 0.3 & 0.31 & 0.31 & 0.32 & 0.078 \\
\hline MMER & 0.40 & 0.41 & 0.35 & 0.16 & 0.40 & 0.31 \\
\hline Pred (25) & 35.06 & 41.56 & 31.63 & 40.26 & 35.06 & 74.19 \\
\hline
\end{tabular}

only MMRE but also MdMRE and Pred (25).

The Boxplot of absolute residuals for the various techniques shows that:

- Predictions based on the GREAT_RM model presented statistically significant accurate estimations, measured using absolute residuals, and was confirmed by the results of the boxplot of absolute residuals, as shown in Fig 12.

- The medians for the GREAT_RM techniques applied to the Desharnais dataset are very close to zero, as is clear from the values on the Y-axis, indicating that the estimates were closer to the minimum value.

- The range of absolute residuals of GREAT_RM is smaller.

- On the other hand, the range of absolute residual values for OLS, Ridge, ANN, SVM, and MARS produced the worst individual estimations.

- Extreme values presented in other models affected the estimation process.

\section{WILCOXON Signed Rank Test:}

The p-value in all the cases is greater than 0.05 , as shown in Table 11. Thus, the proposed methods are statistically significant. As a result, all of the proposed methods can be used for software effort estimation.

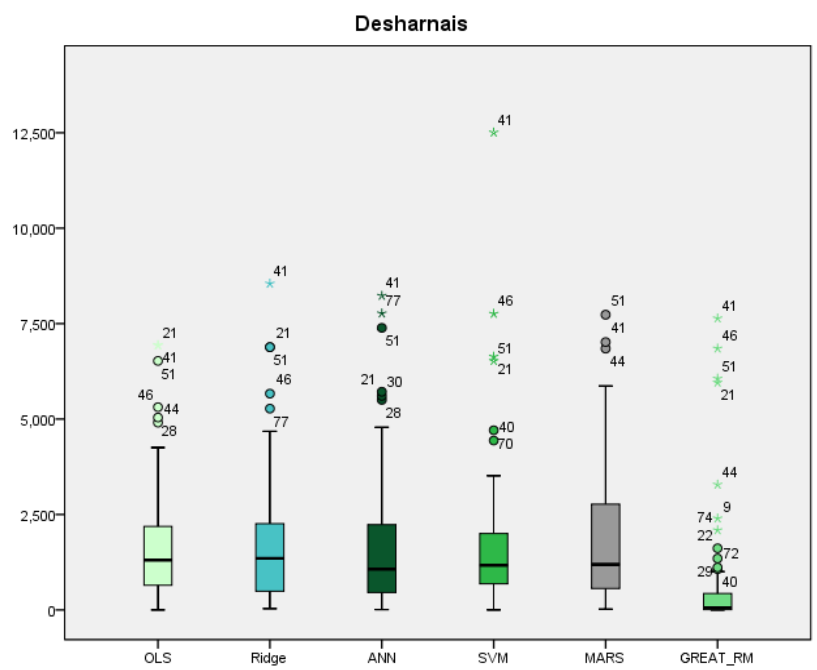

Fig. 12. Boxplot of Absolute Residuals for the Desharnais Dataset 


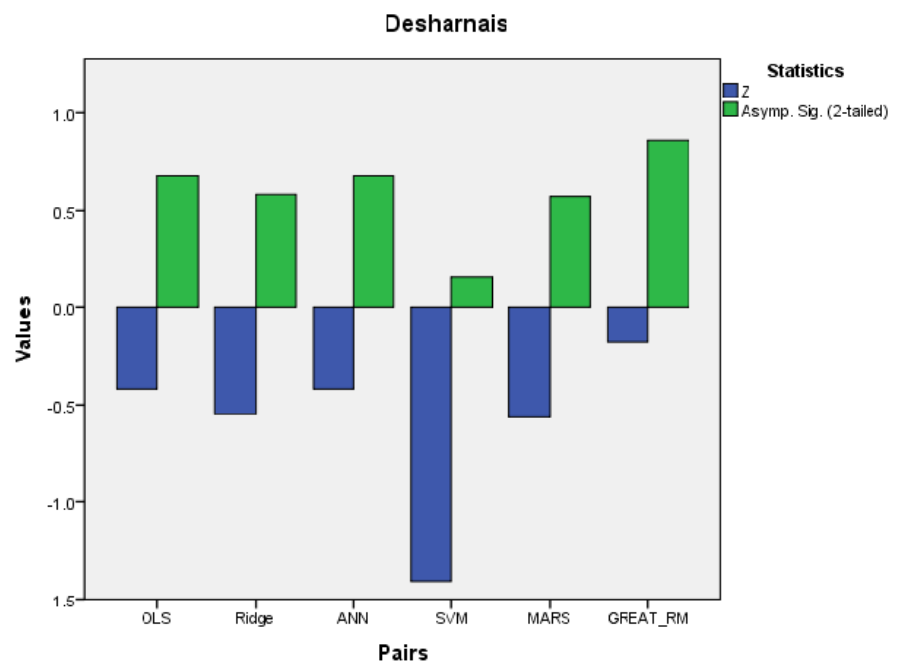

Fig. 13. Bar graph(WILCOXON Signed Rank Test)

Table 11. Wilcoxon Signed Rank Test (Test Statistics ${ }^{\mathrm{C}}$ )

\begin{tabular}{c|c|c|c|c|c|c}
\hline Desharnais Dataset & OLS & Ridge & ANN & SVM & MARS & GREAT_RM \\
\hline Z & $-.419^{\mathrm{a}}$ & $-.551^{\mathrm{a}}$ & $-.419^{\mathrm{a}}$ & $-1.409^{\mathrm{a}}$ & $-.566^{\mathrm{a}}$ & $-.175^{\mathrm{b}}$ \\
\hline Asymp. Sig. (2-tailed) & .675 & .582 & .675 & .159 & .571 & .861 \\
\hline
\end{tabular}

a. Based on positive ranks. b. Based on negative ranks. c. Wilcoxon Signed Rank Test

\subsection{Comparison of the Kemerer Dataset}

Table 12 summarizes the accuracy of the various models in the Kemerer dataset. From the results we can observe that GREAT_RM and ANN performed significantly better than all other models. The results also revealed that both the techniques produced credible results in terms of not only MMRE but also MdMRE, MMER, and Pred (25).

The Boxplot of absolute residuals for the various techniques shows that:

- Predictions based on the GREAT_RM model presented statistically significant accurate estimations, measured using absolute residuals, and was confirmed by the results of boxplot of absolute residuals, as shown in Fig 14.

Table 12. Wilcoxon signed rank test

\begin{tabular}{c|c|c|c|c|c|c}
\hline & OLS & RR & ANN & SVM & MAR Splines & GREAT_RM \\
\hline \multicolumn{7}{c}{ Kemerer Dataset } \\
\hline MMRE & 0.74 & 0.68 & 0.31 & 0.003 & 1.05 & 0.65 \\
\hline MdMRE & 0.54 & 0.37 & 0.12 & 0.0012 & 0.25 & 0.16 \\
\hline MMER & 0.028 & 0.04 & 0.37 & 8.47 & 3.33 & 0.28 \\
\hline Pred (25) & 26.67 & 20 & 66.67 & 100 & 60 \\
\hline
\end{tabular}




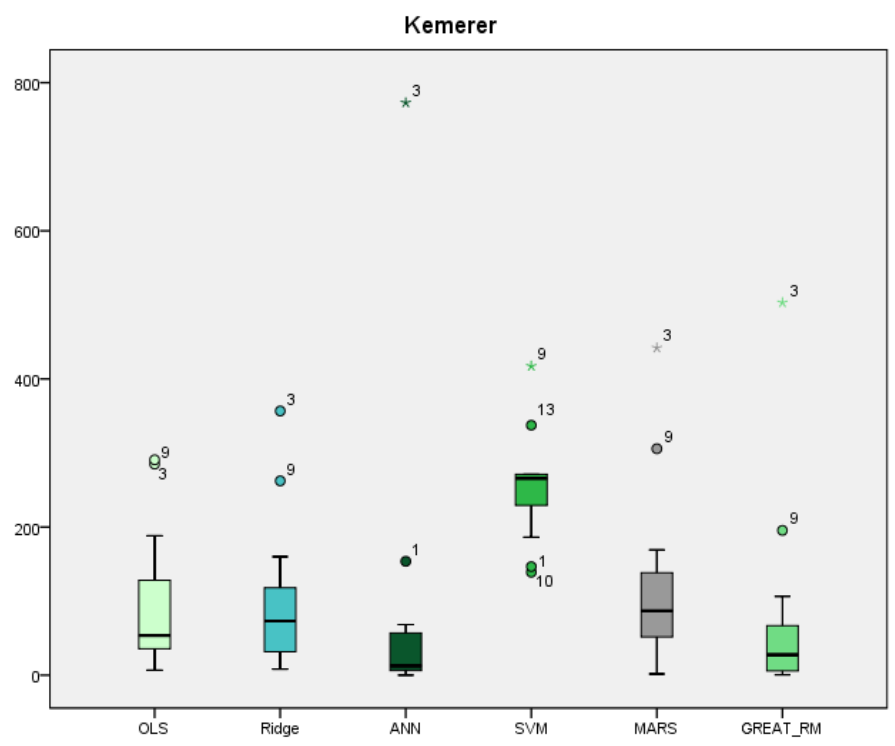

Fig. 14. Boxplot of Absolute Residuals for Kemerer Dataset

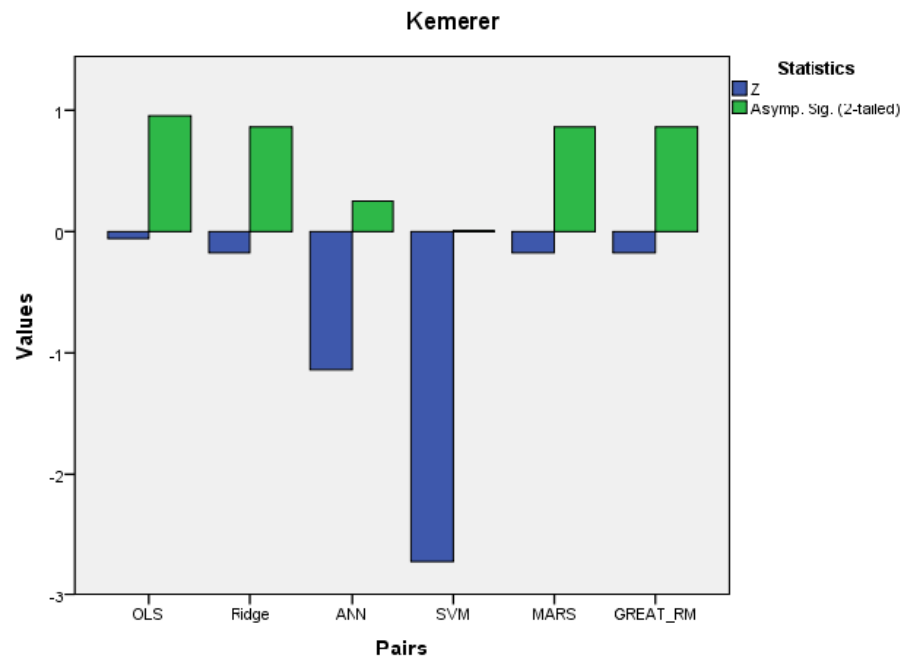

Fig. 15. Bar graph(WILCOXON Signed Rank Test)

- The medians for the GREAT_RM techniques applied to the Kemerer dataset are very close to the median, as is clear from the values on the $\mathrm{Y}$-axis, indicating that the estimates were closer to the minimum value.

- The range of absolute residuals of GREAT_RM is smaller than the absolute residuals of others.

- On the other hand, the range of absolute residual values for SVM produced the worst individual estimations. 
Table 13. Wilcoxon signed rank test $\left(\right.$ Test Statistics $\left.^{\mathrm{C}}\right)$

\begin{tabular}{c|c|c|c|c|c|c}
\hline Kemerer Dataset & OLS & Ridge & ANN & SVM & MARS & GREAT_RM \\
\hline Z & $-.419^{\mathrm{a}}$ & $-.551^{\mathrm{a}}$ & $-.419^{\mathrm{a}}$ & $-1.409^{\mathrm{a}}$ & $-.566^{\mathrm{a}}$ & $-.175^{\mathrm{b}}$ \\
\hline Asymp. Sig. (2-tailed) & .675 & .582 & .675 & .159 & .571 & .861 \\
\hline
\end{tabular}

\section{WILCOXON Signed Rank Test:}

The p-value in all of the cases is greater than 0.05 , as shown in Table 13. Thus, the proposed methods are statistically significant.

\section{Comparison OF GREAT_RM With Other Estimation Methods}

To ensure impartial assessment between our model and previous available results we have taken only those results for comparison that possess the same: (1) validation procedure, (2) number of projects, (3) number of features, and (4) treatment to missing values.

\subsection{Comparison for the Finnish Dataset}

The best results have been achieved with the Finnish dataset, with an MMRE of $10.03 \%$ and a Pred (25) accuracy of $89.47 \%$, with the Fair M-estimator. The lower edge of the boxplot for all cases overlaps the lower whisker. This shows that the data is probably skewed towards the lower end of the scale. The smaller sizes of the box with the robust estimator indicate a reduced variability of absolute residuals.

\subsection{Comparison for the Albrecht Dataset}

On using the proposed methodology with the Albrecht dataset, the best MMRE $=24.16 \%$ and Pred (25) accuracy $=70.83 \%$ with the Huber M-estimator is obtained. This is an MMRE improvement of $36.09 \%$ over the GRACE technique [17], 26.94\% over FGRA [23], and 1.94\% over GRACE+[19]. The prediction accuracy has also been remarkable. There has been an improvement of $18.2 \%$ over GRACE, $20.83 \%$ over GRACE+ and an improvement of $42.23 \%$ over FGRA. In the study, carried out by Shepperd and Schofield [11], that made comparison between regression and analogy estimation models using the Albrecht dataset. The regression model resulted in MMRE $=90 \%$ and Pred $=33 \%$, while analogy obtained MMRE $=62 \%$ and Pred $=33 \%$. Thus, the results achieved by GREAT_RM are significantly better than other estimation methodologies. The results of MdMRE and MMER obtained by the GREAT_RM methodology are mentioned in Table 14.

Table 14. Comparison for the Albrecht Dataset

\begin{tabular}{c|c|c|c|c}
\hline \multicolumn{5}{c}{ Albrecht Dataset } \\
\hline & MMRE & Median MRE & Pred(25) & MMER \\
\hline GREAT_RM & 24.16 & 10 & 70.83 & 22.57 \\
\hline GRACE+ & 26.1 & 24.2 & 50 & \\
\hline FGRA & 51.1 & 48 & 28.6 & 60.4 \\
\hline GRACE & 60.25 & 21.35 & 52.63 & \\
\hline
\end{tabular}




\subsection{Comparison for the COCOMO-81 Dataset}

GRACE [17] used GRA and stepwise regression on the COCOMO 81 dataset. The results obtained using GRA were MMRE $=76.09 \%$ and Pred $(25)=20.63 \%$. The results obtained based on regression were $\mathrm{MMRE}=1540.84 \%$ and $\operatorname{Pred}(25)=6.67 \%$. Dolado [45] used regression and genetic programming and achieved $\mathrm{MMRE}=113 \%$ and $\operatorname{Pred}(25)=17 \%$ with regression, whereas, MMRE $=23.2 \%$ and $\operatorname{Pred}(25)=15 \%$ was obtained using genetic programming. GRACE $^{+}[19]$ used GRA and obtained MMRE $=49.8 \%$ and $\operatorname{Pred}(25)=29 \%$, whereas, the best results of MMRE $=23.2 \%$ and $\operatorname{Pred}(25)=66.7 \%$ have been achieved by Azzeh et al. on using Fuzzy GRA [23]. Using the proposed hybrid analogy technique the finest results were obtained on integrating GRA with stepwise regression. Thus, the result obtained demonstrate its applicability for the COCOMO-81 dataset, as it yielded better results than Song et al.[17, 19], Dolado [45], and Azzeh et al.[23]. The results obtained for MdMRE and MMER using the GREAT_RM methodology are also mentioned in Table 15.

Table 15. Comparison for the COCOMO-81 Dataset

\begin{tabular}{c|c|c|c|c}
\hline \multicolumn{5}{c}{ COCOMO 81 } \\
\hline GREAT_RM & MMRE & Median MRE & Pred(25) & MMER \\
\hline GRACE+ & 21.04 & 9.42 & 76.19 & 48.71 \\
\hline FGRA & 49.8 & 55.2 & 29 & - \\
\hline GRACE & 23.2 & 14.8 & 66.7 & 25.6 \\
\hline
\end{tabular}

\subsection{Comparison for the Desharnais Dataset}

The Desharnais dataset has been extensively used for testing models based on software estimations. GRACE by Song et al. [17] obtained an MMRE of $49.83 \%$ with a Pred (25) accuracy of 30\% with the Desharnais dataset. Mair et al. [46] also used analogy and obtained $\mathrm{MMRE}=57 \%$. Shepperd [11] on using the Desahrnais dataset achieved MMRE $=64 \%$ and Pred $(25)=36 \%$. Mair and Shepperd [46], however, used the hold out strategy, whereas, Song et al. and Azzeh used the jackknifing technique for GRACE ${ }^{+}[19]$ by Song et al. and obtained MMRE $=49.83 \%$ and Pred(25) $=30 \%$. The finest results so far have been by Azzeh et al. [23] with using Fuzzy GRA and they obtained the lowest MMRE $=30 \%$ and a Pred (25) as high as 64.7. The results obtained by using the GREAT_RM techniques have been superior to all the results mentioned above with an MMRE as low as $16.78 \%$ and Pred (25) as high as $74.02 \%$ when using GRA with stepwise regression. The GRA, when applied with OLS, also produced good results, as shown in Table 1. Thus, the result obtained demonstrates its applicability for the Deshanais dataset, yielding better results than those by Song et al. [17] and Azzeh et al. [23].

Table 16. Comparison for the Desharnais Dataset

\begin{tabular}{c|c|c|c|c}
\hline \multicolumn{5}{c}{ Desharnais Dataset } \\
\hline & MMRE & Median MRE & Pred(25) & MMER \\
\hline GREAT_RM & 16.78 & 7.84 & 74.02 & 31.63 \\
\hline GRACE+ & 41.4 & 29.2 & 45.3 & - \\
\hline FGRA & 30.6 & 17.5 & 64.7 & 34.4 \\
\hline GRACE & 49.83 & 33.93 & 30 & - \\
\hline
\end{tabular}


With the OLS method, applied to the GRA, the dataset obtained equally good results with an MMRE of $18.19 \%$ with a Pred (25) of $90.9 \%$. This is an MMRE improvement of $31.64 \%$ over GRACE, 12.41 over FGRA, and 23.21 over GRACE ${ }^{+}$. The results of MdMRE and MMER obtained by the GREAT_RM methodology are also mentioned in Table 16.

\subsection{Comparison for the Kemerer Dataset}

For the Kemerer dataset, the FairM-estimator obtained the best results when used with GRA. MMRE of $29.63 \%$ and a Pred (25) accuracy of $60 \%$ is an MMRE improvement of $29.2 \%$ over GRACE [17], 6.57\% over FGRA [23], and with a Pred (25) accuracy improvement of $33.33 \%$ over GRACE [17] and 7.1\% over FGRA [23]. The results however didn't improve over GRACE $^{+}$. This may be because of the very small size of the dataset and may also be due to the feature selection process and outlier detection performed by Song et al.[19].

Table 17. Comparison for the Kemerer Dataset

\begin{tabular}{c|c|c|c|c}
\hline \multicolumn{5}{c}{ Kemerer Dataset } \\
\hline GREAT_RM & MMRE & Median MRE & Pred(25) & MMER \\
\hline GRACE+ & 29.63 & 16.56 & 60 & 27.93 \\
\hline FGRA & 19.6 & 13.8 & 78.6 & - \\
\hline GRACE & 36.2 & 33.2 & 52.9 & 34.3 \\
\hline
\end{tabular}

\section{THREATS TO VALIDITY}

There are two types of threats to validity. One is the threat to internal validity and the second is the threat to external validity. The external validity is more crucial with respect to the internal validity as they are related to the generalization ability of the predicted models. For five publicly available datasets it has been cleared that the new proposed model achieved by integrating GRA and regression has improved predictive power, which is better than with the other conventional estimation methods, but we have not analyzed how a smaller or larger dataset than those used in the study would yield consistent results. The results have been shown consistent for sample sizes ranging from 15 to 77 samples. We do not think that increasing the sample size beyond this range would show any inconsistent results. The threats to validity can however be reduced by conducting more studies across varied datasets.

\section{CONCLUSION}

Producing accurate software estimates has always been a challenge, where no one method has established itself to the fullest to consistently deliver an accurate estimate. Analogy based estimation is still one of the most extensively used methods in the industry. It is based on finding efforts for similar projects from the project repository.

The proposed hybrid $E b A$ methodology has certainly improved the estimation process. The results obtained on applying the proposed methodology to five publically available datasets for software effort estimation have been presented in the previous section. The results obtained are compared to various types of linear regression models like OLS, ridge regression, etc., and to 
nonlinear models like neural networks, support vector machines, and Multivariate Adaptive Regression Splines (MAR Splines), etc. The results obtained using GREAT_RM are not only better but are also encouraging with a lower MMRE, MdMRE, MMER, and higher Pred (25) for five publicly available datasets. The results are also significant when compared to three well known estimation models of GRACE, FGRA, and GRACE ${ }^{+}$.The results based on the Wilcoxon signed rank test for residuals illustrates that most of the models using GREAT_RM produced statistically accurate predictions as their medians are not statistically different from the hypothesized median.

The empirical evaluations have revealed that the GREAT_RM techniques can certainly enhance the estimation process and hence can be used as an alternative technique for early stage software estimation where the data is uncertain. The results obtained are also finer over our previous results wherein the value of $k$ was fixed for each reference project [48].

This methodology can further be explored on some other large datasets with resampling methods in order to further enhance the validity of the produced results. This methodology can be worked out using other robust regression techniques like S-estimator, Least Trimmed Square or MM-estimator etc. Attribute weighting can also be incorporated along with feature selection, in order to study the impact of individual features on the prediction accuracy.

\section{REFERENCES}

[1] J. L. Deng, “Control problems of grey system”. System and Control Letters, Vol.1, 1982, pp.288-94.

[2] J.Deng,. "Introduction to Grey System theory", The Journal of Grey System,Vol.1, No.1, 1989, pp.1-24.

[3] J.Deng, "Grey information space", The Journal of Grey System Vol.1, No.1, 1989, pp.103-117.

[4] J. M. Jou, P. Y.Chen, and J. M.Sun, "The grey prediction search algorithm for block motion estimation". IEEE Transactions on Circuits and Systems for Video Technology, Vol.9, No.6, 1999, pp.843-848.

[5] S. L. Su, Y. C. Su, and J. F.Huang, "Grey-based power control for DS-CDMA cellular mobile systems". IEEE Transactions on Vehicular Technology, Vol.49, No.6,2000, pp.2081-2088.

[6] B.C.Jiang, , S. L.Tasi and C. C.Wang, "Machine vision-based gray relational theory applied to IC marking inspection". IEEE Transactions on Semiconductor Manufacturing, Vol.15, No.4, 2002, pp.531-539

[7] R. C.Luo, T. M.Chen, and K. L. Su, "Target tracking using a hierarchical grey-fuzzy motion decision making method". IEEE Transactions on Systems, Man and Cybernetics, Part A, Vol.31, No.3, 2001, pp.179-186.

[8] Y. F.Wang, "On-demand forecasting of stock prices using a real-time predictor". IEEE Transactions on Knowledge and Data Engineering, Vol.15, No.4, 2003, pp.1033-1037.

[9] S. J.Huang and C. L.Huang, "Control of an inverted pendulum using grey prediction model". IEEE Transactions on Industry Applications, Vol.36, No.2, 2000, pp.452-458.

[10] T. Mukhopadhyay, S. Vicinanza and M .J. Prietula, "Examining the feasibility of a case-based reasoning model for software effort estimation", MIS Quarterly, Vol.16, No.2, 1992, pp.155-171.

[11] M. J. Shepperd and C.Schofield, "Estimating Software Project Effort Using Analogies", IEEE Transaction on Software Engineering ,Vol.23, 1997, pp.736-743.

[12] L. Angelis, I. Stamelo, “A simulation tool for efficient analogy based cost estimation, ” Empirical Software Engineering, Vol.5, 2000, pp.35-68.

[13] J.W. Keung, B. A. Kitchenham, D. R. Jeffery, "Analogy-X:Providing Statistical Inference to AnalogyBased Software Cost Estimation”, IEEE Transactions on Software Engineering, Vol.34, No.4, 2008.

[14] B. Baskeles, B. Turhan, A. Bener, "Software effort estimation using machine learning methods," 22nd international symposium on Computer and information sciences, 2007, pp.1-6.

[15] A. Idri, A. Abran, T. M. Khoshgoftaar, "Estimating Software Project Effort by Analogy Based on Linguistic Values,", Eighth IEEE International Symposium on Software Metrics (METRICS'02), 2002, pp. 21 . 
[16] M. Azzeh, D. Neagu and P. I. Cowling, "Analogy-based software effort estimation using Fuzzy numbers”. Journal of Systems and Software, Vol.84, No.2, 2011, pp.270-284 [doi: 10.1016/j.jss.2010. 09.028]

[17] Q.Song, M.Shepperd and C.Mair,"Using Grey Relational Analysis to Predict Software Effort with Small Data Sets". Proceedings of the 11th International Symposium on Software Metrics (METRICS'05), 2005, pp.35-45.

[18] C. J. Hsu and C. Y. Huang, "Comparison and Assessment of Improved Grey Relation Analysis for Software Development Effort Estimation," Proceedings of the 3rd International Conference on Management of Innovation and Technology (ICMIT'06), 2006, pp.663-667.

[19] Q.Song and M. J.Shepperd, "Predicting software project effort: A grey relational analysis based method”. Expert Syst. Appl. Vol.38, No.6, 2011, pp.7302-7316. [ doi:10.1016/j.eswa.2010.12.005]

[20] S. J. Huang, N. H. Chiu and L.W. Chen, "Integration of the grey relational analysis with genetic algorithm for software effort estimation". European Journal of operational and research Vol.188, 2007, pp.898-909. [doi:10.1145/1540438.1540440]

[21] M. V. Kosti, N. Mittas, L. Angelis, “ DD-EbA: An algorithm for determining the number of neighbors in cost estimation by analogy using distance distributions", 3d Artificial Intelligence Techniques in Software Engineering Workshop, 7 October, 2010, Larnaca, Cyprus.

[22] G. Li, J.Ruhe, A. Al-Emran and M.M.Richter, "A flexible method for software effort estimation by analogy”, Empirical Software Engineering, Vol.12, No.65, 2007, pp.106. [doi:10.1007/s10664-0067552-4]

[23] M. Azzeh, D. Neagu and P. I. Cowling, "Fuzzy grey relational analysis for software effort estimation", Journal of Empirical software Engineering, Vol.15, No.1, 2010. [ doi:10.1007/s10664-009-9113-0]

[24] K. Srinivasan and D. Fisher, "Machine Learning Approaches to Estimating Software Development Effort," IEEE Trans. Software Eng., Vol.21, No.2, 1995, pp.126-137.

[25] G. Wittig and G. Finnie, "Estimating Software Development Effort with Connectionist Models," Information and Software Technology, Vol.39, No.7, 1997, pp.469-476.

[26] C. Burgess and M. Lefley, "Can Genetic Programming Improve Software Effort Estimation? A Comparative Evaluation," Information and Software Technology, Vol.43, 2001, pp.863-873.

[27] Y. Shan, R.J. McKay, C. J. Lokan and D.L. Essam, "Software Project Effort Estimation Using Genetic Programming", IEEE, Available at: http://www.isbsg.org.au, 2002.

[28] A.Idri, A. Abran and T. M. Khoshgoftaar, "Estimating Software Project Effort by Analogy Based on Linguistic Values”, Eighth IEEE International Symposium on Software Metrics (METRICS'02), 2002.

[29] X. Huang, L. F. Capretz and J. Ren, "A Neuro Fuzzy Model for Software Cost Estimation", Proceedings of the third International Conference on Quality Software (QSIC'03) 0-7695 2015-4/03, IEEE, 2003.

[30] Z. Chen, T. Menzies, D. Port, and B. Boehm, "Feature Subset Selection Can Improve Software Cost Estimation Accuracy," ACM SIGSOFT Software Eng. Notes, Vol.30, No.4, 2005, pp.1-6

[31] P. Sentas, L. Angelis, I. Stamelos, and G. Bleris, "Software Productivity and Effort Prediction with Ordinal Regression," Information and Software Technology, Vol.47, 2005, pp.17-29.

[32] A. F. Sheta, "Estimation of the COCOMO Model Parameters Using Genetic Algorithms for NASA Software Projects", Journal of Computer Science 2 (2): 118-123, ISSN 1549-3636, 2006.

[33] M. Auer, A. Trendowicz, B. Graser, E. Haunschmid, and S. Biffl,'Optimal Project Feature Selection Weigths in Analogy-Based Cost Estimation: Improvement and Limitations," IEEE Trans.Software Eng., Vol.32, No.2, 2006, pp.83-92.

[34] N.-H. Chiu and S.-J. Huang, "The Adjusted Analogy-Based Software Effort Estimation Based on Similarity Distances,” The J. Systems and Software, Vol.80, 2007, pp.628-640.

[35] K. Chaudhary, "GA Based Optimization of Software Development Effort Estimation", GA Based Optimization of Software Effort Estimation, IJCSI, Vol.1, 2010, pp.38-40.

[36] M. Azzeh, D. Neagu and P. Cowling, "Improving Analogy Software Effort Estimation using Fuzzy Feature Subset Selection Algorithm”, PROMISE'08 ,Leipzig, Germany, 2008.

[37] V. Ch, M.K. Hari, T. S. Sethi, B. S. S. Kaushal and A. Sharma, "CPN-A Hybrid Model for Software Cost Estimation", 978-1-4244-9477-4/11, IEEE, 2011. 
[38] P. J. Huber, "Robust Estimation of a Location Parameter". Annals of Mathematical Statistics, Vol.35, 1964, pp.73-101.

[39] P. J. Huber, Robust regression: Asymptotics, conjectures and Monte Carlo, The Annals of Statistics, Vol.1, 1981, pp.799-821.

[40] D.F.Andrews, P.J. Bickel, F. R. Hampel, P.J. Huber, W.H. Rogers and J. W.Tukey, Robust Estimates of Location: Survey and Advances. Princeton University Press, Princeton, New Jersey,1972.

[41] MATLAB ${ }^{\circledR}$ Documentation, http://www.mathworks.com/help/techdoc/

[42] G.A.N.Mbamalu and M.E.El. Hawary, "Load Forecasting via Suboptimal Seasonal Autoregressive models and Iteratively Reweighted Least Squares Estimation" IEEE Transactions on Power Systems,Vol.8, No.1, 1993, pp.343-347.

[43] V.Verardi, and C. Croux, "Robust regression in Stata", Stata Journal, StataCorp LP, Vol.9, No.3, 2009, pp.439-453.

[44] PROMISE Repository of empirical software engineering data http://promisedata.org/ repository

[45] Dolado JJ (2001) "On the problem of the software cost function". Journal of Information and Software Technology, Vol.43, pp.61-72.

[46] Mair C, Kadoda G, Lefley M, Phalp K, Schofield C, Shepperd M, Webster S , "An investigation of machine learning based prediction systems". J Syst Software, Vol.53, 2000, pp.23-29.

[47] G. Nagpal, M. Uddin and A. Kaur, "A hybrid technique using Grey Relational analysis and Regression for Software Effort Estimation using Feature Selection" International Journal of Soft Computing and Engineering (IJSCE), Vol.1, No.6, 2012.

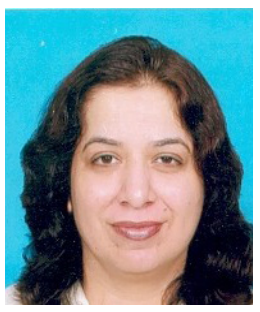

\section{Geeta Nagpal}

Geeta Nagpal, pursuing Ph D programme in the Department of Computer Science and Engineering, National Institute of Technology, Jalandhar, INDIA. She completed her Master's degree in Computer Science from Punjab Agricultural University, Ludhiana. She is presently working as Associate Professor in the Department of Computer Science and Engineering at National Institute of Technology, Jalandhar. Her research interests are Software Engineering, Databases and Data mining.

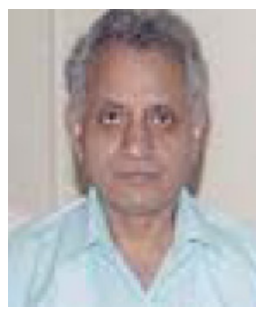

\section{Prof. Moin Uddin}

Prof. Moin Uddin, Pro Vice Chancellor, Delhi Technological University, Delhi , INDIA. He obtained his B.Sc. Engineering and M.Sc. Engineering (Electrical) from AMU, Aligarh in 1972 and 1978 respectively. He obtained hid Ph. D degree from University of Roorkee, Roorkee in 1994. Before Joining as the Pro Vice Chancellor of Delhi Technological University, he was the Director of NIT, Jalandhar for five years. He has worked as Head Electrical Engineering Department and Dean Faculty of Engineering and Technology at Jamia Millia Islamia (Central University) NewDelhi. He supervised $14 \mathrm{Ph}$. D thesis and more than $30 \mathrm{M}$.Tech dissertations. He has published more than 40 research papers in reputed journals and conferences. Prof. Moin Uddin holds membership of many professional bodies. He is a Senior Member of IEEE. 


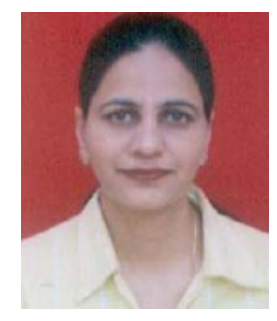

\section{Dr. Arvinder Kaur}

Dr. Arvinder Kaur, Associate Professor, University School of IT, Guru Gobind Singh Indraprastha University,Delhi, India. She completed her masters degree in Computer Science from Thapar Institute of Engineering and Technology and $\mathrm{Ph}$ D from Guru Gobind Singh Indraprastha University,Delhi. Prior to joining the school, she worked with Dr. B. R. Ambedkar Regional Engineering College, Jalandhar and Thapar Institute of Engineering and Technology. Her research interests include Software Engineering, Object-Oriented Software Engineering, Software Metrics, Microprocessors, Operating Systems, Artificial Intelligence, and Computer networks. She is a lifetime member of ISTE and CSI. She is also a member of ACM. She has published 45 research papers in national and international journals and conferences. Her paper titled, "Analysis of object oriented Metrics"was published as a chapter in the book Innovations in Software Measurement (ShakerVerlag, Aachen 2005). 